\title{
Potassium Model for Slow (2-3 Hz) In Vivo Neocortical Paroxysmal Oscillations
}

\author{
M. Bazhenov, ${ }^{1}$ I. Timofeev, ${ }^{2}$ M. Steriade, ${ }^{2}$ and T. J. Sejnowski ${ }^{1,3}$ \\ ${ }^{1}$ The Salk Institute, Howard Hughes Medical Institute, Computational Neurobiology Laboratory, La Jolla, California 92037; ${ }^{2}$ Laboratory \\ of Neurophysiology, School of Medicine, Laval University, Quebec G1K 7P4, Canada; and ${ }^{3}$ Department of Biology, University of \\ California San Diego, La Jolla, California 92093
}

Submitted 2 June 2003; accepted in final form 22 March 2004

Bazhenov, M., I. Timofeev, M. Steriade, and T. J. Sejnowski. Potassium model for slow $(2-3 \mathrm{~Hz})$ in vivo neocortical paroxysmal oscillations. J Neurophysiol 92: 1116-1132, 2004. First published March 31, 2004; 10.1152/jn.00529.2003. In slow neocortical paroxysmal oscillations, the de- and hyperpolarizing envelopes in neocortical neurons are large compared with slow sleep oscillations. Increased local synchrony of membrane potential oscillations during seizure is reflected in larger electroencephalographic oscillations and the appearance of spike- or polyspike-wave complex recruitment at 2to $3-\mathrm{Hz}$ frequencies. The oscillatory mechanisms underlying this paroxysmal activity were investigated in computational models of cortical networks. The extracellular $\mathrm{K}^{+}$concentration $\left(\left[\mathrm{K}^{+}\right]_{\mathrm{o}}\right)$ was continuously computed based on neuronal $\mathrm{K}^{+}$currents and $\mathrm{K}^{+}$pumps as well as glial buffering. An increase of $\left[\mathrm{K}^{+}\right]_{\mathrm{o}}$ triggered a transition from normal awake-like oscillations to 2 - to $3-\mathrm{Hz}$ seizure-like activity. In this mode, the cells fired periodic bursts and nearby neurons oscillated highly synchronously; in some cells depolarization led to spike inactivation lasting $50-100 \mathrm{~ms} . \mathrm{A}\left[\mathrm{K}^{+}\right]_{\mathrm{o}}$ increase, sufficient to produce oscillations could result from excessive firing (e.g., induced by external stimulation) or inability of $\mathrm{K}^{+}$regulatory system (e.g., when glial buffering was blocked). A combination of currents including high-threshold $\mathrm{Ca}^{2+}$, persistent $\mathrm{Na}^{+}$and hyperpolarization-activated depolarizing $\left(I_{\mathrm{h}}\right)$ currents was sufficient to maintain $2-$ to $3-\mathrm{Hz}$ activity. In a network model that included lateral $\mathrm{K}^{+}$diffusion between cells, increase of $\left[\mathrm{K}^{+}\right]_{0}$ in a small region was generally sufficient to maintain paroxysmal oscillations in the whole network. Slow changes of $\left[\mathrm{K}^{+}\right]_{\mathrm{o}}$ modulated the frequency of bursting and, in some case, led to fast oscillations in the 10 - to $15-\mathrm{Hz}$ frequency range, similar to the fast runs observed during seizures in vivo. These results suggest that modifications of the intrinsic currents mediated by increase of $\left[\mathrm{K}^{+}\right]_{\mathrm{o}}$ can explain the range of neocortical paroxysmal oscillations in vivo.

\section{IN T R O D UCTION}

Although it is well established that the extracellular potassium concentration $\left(\left[\mathrm{K}^{+}\right]_{\mathrm{o}}\right)$ increases during epileptogenesis (Moody et al. 1974), whether this is the primary seizureeliciting factor, or the increased firing causes the $\left[\mathrm{K}^{+}\right]_{\mathrm{o}}$ elevation, remains unknown. According to the Grafstein potassium hypothesis, $\mathrm{K}^{+}$released during intense neuron firing can accumulate in the interstitial space, thus depolarizing neurons and leading to spike inactivation. Slow diffusion of $\mathrm{K}^{+}$into surrounding areas could then depolarize neurons and create slowly propagating waves of spreading depression (SD) (Grafstein 1957). Delayed increase of $\left[\mathrm{K}^{+}\right]_{\mathrm{o}}$ compared with membrane potential depolarization measured during SD propaga-

Address for reprint requests and other correspondence: M. Bazhenov, The Salk Institute for Biological Studies, 10010 N. Torrey Pines Rd., La Jolla, CA 92037 (E-mail: bazhenov@salk.edu). tion (Herreras and Somjen 1993) suggests, however, that $\mathrm{K}^{+}$ diffusion may not be the primary mechanism maintaining SD waves, but it might still trigger SD phenomena (Kager et al. 2000).

Modulation of $\left[\mathrm{K}^{+}\right]_{\mathrm{o}}$ has a profound impact on the excitability of neurons and neuronal networks. Increase of $\left[\mathrm{K}^{+}\right]_{\mathrm{o}}$ depolarizes the $\mathrm{K}^{+}$currents reversal potential and can affect the maximal conductances of some depolarizing currents such as the hyperpolarization-activated depolarizing current $\left(I_{\mathrm{h}}\right)$ (Spain et al. 1987) and the persistent sodium current $\left(I_{\mathrm{Na}(\mathrm{p})}\right)$ (Somjen and Muller 2000), increasing excitability. A recent study showed that $\mathrm{K}^{+}$-mediated increase of $I_{\mathrm{h}}$ may lead to periodic bursting in a cortical network model (Timofeev et al. 2002a). Periodic bursting was found in vitro after increasing $\left[\mathrm{K}^{+}\right]_{\mathrm{o}}$ (Jensen and Yaari 1997; Leschinger et al. 1993; Pan and Stringer 1997). Traumatic brain injury leading to loss of $\mathrm{K}^{+}$ conductance in hippocampal glia can result in the failure of glial $\mathrm{K}^{+}$homeostasis and abnormal neuronal function including seizures (D’Ambrosio et al. 1999).

The Lennox-Gastaut syndrome is one of the most severe and difficult epileptic conditions (Niedermeyer 2002). The electroencephalographic (EEG) pattern for this type of seizure consists of slow spike-wave (SW) or polyspike-wave (PSW) complexes and runs of rapid EEG "spikes" (10-25/s). This pattern closely resembles paroxysmal oscillations observed in experiments with anesthetized and chronic animals, consisting of SW/PSW complexes recurring at 2-3 Hz, often interrupted by fast runs at $10-15 \mathrm{~Hz}$ (Steriade et al. 1998a). The thalamic or cortical origin of these seizures is still actively debated. The occurrence of SW complexes in the depths of monkey cortex without a reflection at the cortical surface (Steriade 1974) and observation of seizures with SW/PSW complexes in completely isolated cortical slabs in vivo (Timofeev et al. 1998) suggest that focal SW seizure are initiated within the cortex. Multi-site recordings show that SW/PSW seizures may be initiated in cortex and then spread to the thalamus after a few-second delay (Neckelmann et al. 1998). Dual recordings from cortex and thalamus indicate that thalamic reticular neurons faithfully follow each cortical EEG "spike," whereas target thalamocortical (TC) neurons are relatively hyperpolarized during seizure episodes with SW/PSW complexes and thus cannot enhance paroxysmal bursting (Neckelmann et al. 1998; Steriade and Contreras 1995, 1998; Steriade et al. 1998a; Timofeev et al. 1998). Intracellular recordings from TC neurons during $\mathrm{SW}$ discharges in genetic models of absence

\footnotetext{
The costs of publication of this article were defrayed in part by the payment of page charges. The article must therefore be hereby marked "advertisement" in accordance with 18 U.S.C. Section 1734 solely to indicate this fact.
} 
epilepsy in rats also demonstrated that a majority of TC cells $(>90 \%)$ were tonically hyperpolarized (Pinault et al. 1998).

This paper is a computational study of intracortical mechanisms for generating paroxysmal oscillations. We demonstrate an increased neuronal firing prior to seizure in vivo and we study with a computational network model whether local increases of $\left[\mathrm{K}^{+}\right]_{\mathrm{o}}$, either after intensive neuronal firing or when $\mathrm{K}^{+}$regulatory system fail to maintain $\left[\mathrm{K}^{+}\right]_{\mathrm{o}}$ level, can explain the observed transition to $2-$ to $3-\mathrm{Hz}$ paroxysmal bursting in the cortical network.

\section{METHODS}

\section{In vivo recordings}

Intracellular recordings from neocortical neurons were performed in 16 cats anesthetized with ketamine-xylazine $(10-15$ and $2-3 \mathrm{mg} / \mathrm{kg}$ im). After ketamine-xylazine anesthesia, $\sim 30 \%$ of cats $(n=6)$ displayed spontaneous electrographic seizures consisting of SW/PSW complexes at $1.5-3 \mathrm{~Hz}$, often associated with fast runs at $\sim 10-15 \mathrm{~Hz}$. Details of surgery are described in the companion paper (Timofeev et al. 2004).

Focal field potentials and multiunit recordings were obtained by means of an array of six equally spaced tungsten electrodes inserted in the cortex with an angle $45^{\circ}$ arranged in the way that tips of all electrodes were aligned perpendicular to cortical surface and that the most superficial electrode was at depth $\sim 100 \mu \mathrm{m}$ and the deepest electrode was at depth $\sim 1.6 \mathrm{~mm}$. Intracellular recordings from cortical neurons were obtained with sharp glass micropipettes having resistance of 30-80 M $\Omega$. The intracellular pipette was lowered in the cortical depth at distances $<500 \mu \mathrm{m}$ from the tips of tungsten electrodes composing the array. All experimental procedures were performed according to national guidelines and were approved by the committee for animal care of Laval University.

\section{Computational model}

Models of cortical pyramidal (PY) cells and interneurons (INs) had two compartments with channels governed by Hodgkin-Huxley kinetics (Mainen and Sejnowski 1996):

$$
C_{\mathrm{m}} \frac{\mathrm{d} V_{\mathrm{D}}}{\mathrm{d} t}=-g_{\mathrm{L}}\left(V_{\mathrm{D}}-E_{\mathrm{L}}\right)-g\left(V_{\mathrm{D}}-V_{\mathrm{S}}\right)-I_{\mathrm{D}}^{\mathrm{int}}-I^{\mathrm{snn}}, g\left(V_{\mathrm{S}}-V_{\mathrm{D}}\right)=-I_{\mathrm{S}}^{\mathrm{int}}
$$

where $C_{\mathrm{m}}, g_{\mathrm{L}}$ are the membrane capacitance and the leakage conductance of the dendritic compartment, $E_{\mathrm{L}}$ is the reversal potential, $V_{\mathrm{D}}$ and $V_{\mathrm{S}}$ are the membrane potentials of dendritic and axo-somatic compartments, $I_{\mathrm{D}}^{\text {int }}$ and $I_{\mathrm{S}}^{\text {int }}$ are the sums of active intrinsic currents in axo-somatic and dendritic compartments, $I^{\text {syn }}$ is a sum of synaptic currents, and $g$ is the conductance between axo-somatic and dendritic compartments. In this model, the axo-somatic compartment had no capacitance, which sped up the simulations but had little effect on the spike firing patterns (Mainen and Sejnowski 1996).

The model included fast $\mathrm{Na}^{+}$channels, $I_{\mathrm{Na}}$, with a high density in the axo-somatic compartment and a low density in the dendritic compartment. A fast delayed rectifier potassium $\mathrm{K}^{+}$current, $I_{\mathrm{K}}$, was present in the axo-somatic compartment. A persistent sodium current, $I_{\mathrm{Na}(\mathrm{p})}$, was included in the axo-somatic and dendritic compartments (Alzheimer et al. 1993; Kay et al. 1998). A slow voltage-dependent noninactivating $\mathrm{K}^{+}$current, $I_{\mathrm{Km}}$, a slow $\mathrm{Ca}^{2+}$-dependent $\mathrm{K}^{+}$current, $I_{\mathrm{K}(\mathrm{Ca})}$, a high-threshold $\mathrm{Ca}^{2+}$ current, $I_{\mathrm{Ca}}$, hyperpolarization-activated depolarizing current $I_{\mathrm{h}}$ were included in the dendritic compartment. A potassium leak current, $I_{\mathrm{KL}}=g_{\mathrm{KL}}\left(V-E_{\mathrm{K}}\right)$, was included in the dendritic and axo-somatic compartments. For $I_{\mathrm{Na}(\mathrm{P})}, I_{\mathrm{Na}(\mathrm{p})}=g_{\mathrm{Na}(\mathrm{p})}$ $m(V-50), \mathrm{d} m / \mathrm{d} t=\left(m_{\infty}-m\right) / 0.2, m_{\infty}=1 /\{1+\exp [-(V+42) / 5]\}$ (Alzheimer et al. 1993). For $I_{\mathrm{h}}, I_{\mathrm{h}}=g_{\mathrm{h}}\left(0.8 m_{1}+0.2 m_{2}\right)(V+40)$, $\mathrm{d} m_{\mathrm{i}} / \mathrm{d} t=-\left(m_{\infty}-m_{\mathrm{i}}\right) / \tau_{\mathrm{i}}, m_{\infty}=1 /\{1+\exp [(V+82) / 7]\}, \tau_{1}=38 \mathrm{~ms}$, $\tau_{2}=319 \mathrm{~ms}$ (Spain et al. 1987). The slow $I_{\mathrm{h}}$ component $\left(\tau_{2}\right)$ was found to have little effect on the firing patterns and was omitted in these simulations. The expressions for the voltage- and $\mathrm{Ca}^{2+}$-dependent transition rates for all other currents are given in (Timofeev et al. 2000). In most of the simulations, the maximal conductances and passive properties were $S_{\text {soma }}=1.0 \cdot 10^{-6} \mathrm{~cm}^{2}$ (Mainen and Sejnowski 1996), $g_{\mathrm{Na}}=3,000 \mathrm{mS} / \mathrm{cm}^{2}$ (Mainen and Sejnowski 1996), $g_{\mathrm{K}}=200 \mathrm{mS} / \mathrm{cm}^{2}$ (Mainen and Sejnowski 1996), $g_{\mathrm{KL}}=0.1 \mathrm{mS} / \mathrm{cm}^{2}$, $g_{\mathrm{Na}(\mathrm{p})}=0.07 \mathrm{mS} / \mathrm{cm}^{2}$ (Kay et al. 1998) for axo-somatic compartment and $C_{\mathrm{m}}=0.75 \mu \mathrm{F} / \mathrm{cm}^{2}$ (Mainen and Sejnowski 1996), $g_{\mathrm{L}}=0.033$ $\mathrm{mS} / \mathrm{cm}^{2}$ (Mainen and Sejnowski 1996), $g_{\mathrm{KL}}=0.01 \mathrm{mS} / \mathrm{cm}^{2}, S_{\mathrm{dend}}=$ $S_{\text {soma }}$ r, $g_{\mathrm{Ca}}=0.022 \mathrm{mS} / \mathrm{cm}^{2}$ (Reuveni et al. 1993), $g_{\mathrm{Na}}=1 \mathrm{mS} / \mathrm{cm}^{2}$ (Mainen and Sejnowski 1996), $g_{\mathrm{K}(\mathrm{Ca})}=2.5 \mathrm{mS} / \mathrm{cm}^{2}, g_{\mathrm{Km}}=0.01$ $\mathrm{mS} / \mathrm{cm}^{2}$ (Gutfreund et al. 1995), $g_{\mathrm{Na}(\mathrm{p})}=0.07 \mathrm{mS} / \mathrm{cm}^{2}$ (Kay et al. 1998), $g_{\mathrm{h}}=0.01-0.02 \mathrm{mS} / \mathrm{cm}^{2}$ (Alzheimer et al. 1993) for dendritic compartment. $g_{\mathrm{K}(\mathrm{Ca})}$ was chosen to prevent membrane potential "lock" in the depolarized state after $\left[\mathrm{K}^{+}\right]_{\mathrm{o}}$ increase. Many of these conductances were systematically varied to find the range for the observed phenomena. $I_{\mathrm{Na}(\mathrm{p})}$ was not included in IN cells. The resistance between compartments was $R=10 \mathrm{M} \Omega$.

Reversal potentials for all $\mathrm{K}^{+}$-mediated currents were calculated using Nernst equation $E_{\mathrm{K}}=26.64 \ln \left(\left[\mathrm{K}^{+}\right]_{\mathrm{o}} /\left[\mathrm{K}^{+}\right]_{\mathrm{i}}\right)$, where $\left[\mathrm{K}^{+}\right]_{\mathrm{o}}$ is extra- and $\left[\mathrm{K}^{+}\right]_{\mathrm{i}}$ is intracellular $\mathrm{K}^{+}$concentrations, $E_{\mathrm{K}}$ is reversal potential in millivolts. $\left[\mathrm{K}^{+}\right]_{\mathrm{i}}$ was held constant at $130 \mathrm{mM}$ through most of the simulations. Reversal potentials for $I_{\mathrm{h}}$ and leak currents were calculated as

$$
\begin{gathered}
E_{\mathrm{h}}=26.64 \ln \left(\left[\mathrm{K}^{+}\right]_{\mathrm{o}}+0.2\left[\mathrm{Na}^{+}\right]_{\mathrm{o}}\right) /\left(\left[\mathrm{K}^{+}\right]_{\mathrm{i}}+0.2\left[\mathrm{Na}^{+}\right]_{\mathrm{i}}\right) \\
E_{\mathrm{L}}=26.64 \ln \left(\left[\mathrm{K}^{+}\right]_{\mathrm{o}}+0.085\left[\mathrm{Na}^{+}\right]_{\mathrm{o}}+0.1\left[\mathrm{Cl}^{-}\right]_{\mathrm{i}}\right) / \\
\left(\left[\mathrm{K}^{+}\right]_{\mathrm{i}}+0.085\left[\mathrm{Na}^{+}\right]_{\mathrm{i}}+0.1\left[\mathrm{Cl}^{-}\right]_{\mathrm{o}}\right)
\end{gathered}
$$

where $\left[\mathrm{Na}^{+}\right]_{\mathrm{o}}=130 \mathrm{mM},\left[\mathrm{Na}^{+}\right]_{\mathrm{i}}=20 \mathrm{mM},\left[\mathrm{Cl}^{-}\right]_{\mathrm{i}}=8 \mathrm{mM}$, $\left[\mathrm{Cl}^{-}\right]_{\mathrm{o}}=130 \mathrm{mM}$. In some simulations, $\left[\mathrm{K}^{+}\right]_{\mathrm{i}},\left[\mathrm{Na}^{+}\right]_{\mathrm{o}}$, and $\left[\mathrm{Na}^{+}\right]_{\mathrm{i}}$ were continuously updated to examine whether they had any effect on the results.

The extracellular $\mathrm{K}^{+}$concentration was continuously updated based on $\mathrm{K}^{+}$currents, $\mathrm{K}^{+}$pumps, $\mathrm{K}^{+}$buffering simulating the glial $\mathrm{K}^{+}$uptake system (Kager et al. 2000) and lateral $\mathrm{K}^{+}$diffusion

$$
\begin{aligned}
\frac{\mathrm{d}\left[\mathrm{K}^{+}\right]_{\mathrm{o}}}{\mathrm{d} t}=k I_{\mathrm{K}}^{\mathrm{\Sigma}} / \mathrm{F} d+G+D / \Delta x^{2}\left(\left[\mathrm{~K}^{+}\right]_{\mathrm{o}(+)}+\left[\mathrm{K}^{+}\right]_{\mathrm{o}(-)}-2\left[\mathrm{~K}^{+}\right]_{\mathrm{o}}\right) \\
+D / \Delta x^{2}\left(\left[K^{+}\right]_{\mathrm{o}(\mathrm{sd})}-\left[\mathrm{K}^{+}\right]_{\mathrm{o}}\right) \\
+
\end{aligned}
$$

where $F=96,489 \mathrm{C} / \mathrm{mol}$ is the Faraday constant, $d=0.15 \mu \mathrm{M}$ is the ratio of extracellular volume (per cell compartment) to the surface area, $k=10$ is the unit conversion constant for currents, $I_{\mathrm{K}}^{\Sigma}$ (in $\left.\mu \mathrm{A} / \mathrm{cm}^{2}\right)$ in is a sum of all $\mathrm{K}^{+}$currents including an inward $\mathrm{K}^{+}$ current produced by active $\mathrm{K}^{+}$pumps (Kager et al. 2000)

$$
I_{\text {pump }}=I_{\max } /\left(1+\left[\mathrm{K}^{+}\right]_{\mathrm{o}(\mathrm{eq})} /\left[\mathrm{K}^{+}\right]_{\mathrm{o}}\right)^{2}
$$

$\left[\mathrm{K}^{+}\right]_{\mathrm{o}(\mathrm{eq})}=3.5 \mathrm{mM}$ is an equilibrium $\left[\mathrm{K}^{+}\right]_{\mathrm{o}}$ concentration, $I_{\max }$ is the maximal flux generated by the pump (to compensate $\mathrm{K}^{+}$leak at resting conditions we selected $I_{\max }=5 \mu \mathrm{A} / \mathrm{cm}^{2}$ for dendritic and $I_{\max }=40 \mu \mathrm{A} / \mathrm{cm}^{2}$ for somatic compartments), $D=410^{-6} \mathrm{~cm}^{2} / \mathrm{s}$ is diffusion coefficient $\left[D=2.5-3.3 \quad 10^{-6} \mathrm{~cm}^{2} / \mathrm{s}\right.$ was estimated for cat neocortex (Fisher et al. 1976)]. In the model, we assumed that each cell compartment had an associated extracellular volume and $\left[\mathrm{K}^{+}\right]_{\mathrm{o}}$ indicates the average concentration within this volume, $\left[\mathrm{K}^{+}\right]_{\mathrm{O}(+)}$ and $\left[\mathrm{K}^{+}\right]_{\mathrm{o}(-)}$ are $\mathrm{K}^{+}$concentrations in the adjacent volumes (corresponding to the neighboring cells), $\left[\mathrm{K}^{+}\right]_{\mathrm{o}(\mathrm{sd})}$ is $\mathrm{K}^{+}$concentrations in the adjacent compartment (soma or dendrites), $G$ is a variable describing the effect of the glial buffering system. In the one-dimensional approximation to diffusion along the $x$ axis, the distance between volume centers was estimated as $\Delta x=100 \mu \mathrm{m}$ based on the assumption that one synaptic footprint (10 cells in the model) corresponded to $\sim 1 \mathrm{~mm}$ in the cortex. In most single cell simulations 
(except Figs. $3 E$ and Fig. 4), the diffusion between somatic and dendritic compartments was set to zero to explore effects of difference in $\left[\mathrm{K}^{+}\right]_{\mathrm{o}}$ between compartments. In the network simulations (Figs. 8-11), the diffusion between compartments was always present and nearly identical levels of $\left[\mathrm{K}^{+}\right]_{\mathrm{o}}$ were maintained in all compartments.

The glial buffering was modeled by first-order kinetics

$$
\begin{aligned}
G=k_{1}\left([\mathrm{~B}]_{\max }-[\mathrm{B}]\right) / k_{1 \mathrm{~N}}-k_{2}\left[\mathrm{~K}^{+}\right]_{\mathrm{o}}[\mathrm{B}] \\
\quad \frac{\mathrm{d}[\mathrm{B}]}{\mathrm{d} t}=k_{1}\left([\mathrm{~B}]_{\max }-[\mathrm{B}]\right)-k_{2}\left[\mathrm{~K}^{+}\right]_{\mathrm{o}}[\mathrm{B}]
\end{aligned}
$$

where $[\mathrm{B}]$ is a free buffer concentration, $[\mathrm{B}]_{\max }=500 \mathrm{mM}$ is total buffer, $[\mathrm{KB}]=[\mathrm{B}]_{\max }-[\mathrm{B}]$ is $\mathrm{K}^{+}$bound to the buffer, $k_{1}=0.0008$ and $k_{2}=k_{1} /\left\{1+\exp \left[\left(\left[\mathrm{K}^{+}\right]_{\mathrm{o}}-\left[\mathrm{K}^{+}\right]_{\mathrm{o}(\mathrm{th})}\right) /(-1.15)\right]\right\}$ are rate constants, $k_{1 \mathrm{~N}}=1.1,\left[\mathrm{~K}^{+}\right]_{\mathrm{o}(\mathrm{th})}=15 \mathrm{mM}$ for soma and $\left[\mathrm{K}^{+}\right]_{\mathrm{o}(\mathrm{th})}=9 \mathrm{mM}$ for dendritic compartment (Kager et al. 2000). The threshold $\left[\mathrm{K}^{+}\right]_{\mathrm{o}}$ concentrations, $\left[\mathrm{K}^{+}\right]_{\mathrm{o}(\mathrm{th})}$, were systematically varied and final values were chosen to achieve steady state levels of $\left[\mathrm{K}^{+}\right]_{\mathrm{o}}$ for two different modes of behavior: silent and tonic firing (see Fig. 2).

The firing properties of the two compartment model in Eq. 1 depend on the coupling conductance between compartments $(g=1 / R$, where $R$ is resistance between compartments) and the ratio of dendritic area to axo-somatic area. The ratio, $r$, controls the firing patterns in the model (Mainen and Sejnowski 1996). We used a model of a regularspiking neuron for PY cells $(r=165)$ and a model of a fast spiking neuron for IN cells $(r=50)$.

\section{Synaptic currents}

All synaptic currents were calculated according to

$$
I_{\mathrm{syn}}=g_{\mathrm{syn}}[\mathrm{O}]\left(V-E_{\mathrm{syn}}\right)
$$

where $g_{\text {syn }}$ is the maximal conductivity, $[\mathrm{O}](t)$ is the fraction of open channels, $E_{\text {syn }}$ is the reversal potential. $E_{\mathrm{AMPA}}^{\mathrm{syn}}=0 \mathrm{mV}$ for AMPA and $N$-methyl-D-aspartate (NMDA) receptors, $E_{\mathrm{GABAA}}^{\mathrm{syn}}=-80 \mathrm{mV}$ for $\mathrm{GABA}_{\mathrm{A}}$ receptors. A simple phenomenological model was used to describe short-term depression of intracortical excitatory connections (Abbott et al. 1997; Galarreta and Hestrin 1998; Timofeev et al. 2000; Tsodyks and Markram 1997). According to this a maximal synaptic conductance was multiplied to depression variable, $D \leq 1$, representing the amount of available "synaptic resources"

$$
D=1-\left(1-D_{\mathrm{i}}(1-U)\right) \exp \left(-\left(t-t_{\mathrm{i}}\right) / \tau\right)
$$

where $U=0.07$ is the fraction of resources used per action potential, $\tau=700 \mathrm{~ms}$ the time constant of recovery of the synaptic resources, $D_{i}$ the value of $D$ immediately before the $i$ th event, and $\left(t-t_{i}\right)$ the time after $i$ th event.

$\mathrm{GABA}_{\mathrm{A}}, \mathrm{NMDA}$, and AMPA synaptic currents were modeled by first-order activation schemes (Destexhe et al. 1994). Dependence on postsynaptic voltage for NMDA receptors was $1 /\left\{1+\exp \left[-\left(V_{\text {post }}-\right.\right.\right.$ $\left.\left.\left.V_{\text {th }}\right) / \sigma\right]\right\}$, where $V_{\text {th }}=-25 \mathrm{mV}, \sigma=12.5 \mathrm{mV}$ (Destexhe et al. 1994; Golomb and Amitai 1997; Traub et al. 1991). The equations for all synaptic currents are given in (Timofeev et al. 2000). The maximal conductances (for each synapse) were $g_{\text {AMPA(PY-PY) }}=0.08-0.15 \mu \mathrm{S}$, $g_{\mathrm{NMDA}(\mathrm{PY}-\mathrm{PY})}=0.01 \mu \mathrm{S}, g_{\mathrm{AMPA}(\mathrm{PY}-\mathrm{IN})}=0.05 \mu \mathrm{S}, g_{\mathrm{NMDA}(\mathrm{PY}-\mathrm{IN})}=$ $0.008 \mu \mathrm{S}, g_{\text {GABAA(IN-PY) }}=0.05 \mu \mathrm{S}$.

\section{Network geometry and stimulation}

The cortical model consisted of a one-dimensional two-layer array of $100 \mathrm{PY}$ and $25 \mathrm{IN}$ cells. This is the simplest possible network geometry capable of displaying a spatial expansion of the bursting activity initiated in a localized focus. Network models including 300 PY and 74 IN neurons were also tested. Varying the size of the inhibitory population versus excitatory one had minimal effect on the network dynamics: other PY to IN ratios (such as equal number of PY and IN neurons) produced similar network dynamics as long as the total inhibitory drive to a given PY cell was strong enough to compensate for excitatory inputs. In most of the simulations, the connection fan out was \pm 5 cells for AMPA and NMDA mediated PY-PY synapses; \pm 1 cell for AMPA and NMDA mediated PY-IN synapses; \pm 5 cells for GABA $_{\mathrm{A}}$ mediated IN-PY synapses. Other radii of synaptic interconnections were used to test the sensitivity of the results. The model geometry is based on assumption that the network size, $N$, is much larger than the number of neurons, $M$, within a synaptic footprint. Some of the intrinsic parameters of the neurons in the network were initialized with random variability (Gaussian distribution with $\sigma=5-10 \%$ ) to ensure the robustness of the results (Bazhenov et al. 1998). In simulations with external input, all the cells in the network were stimulated by Poisson distributed spike trains with an average rate of $10 \mathrm{~Hz}$.

\section{RES U L T S}

\section{Neuronal firing associated with seizures}

In the six experiments in which an array of microelectrodes was inserted in the neocortex and in which simultaneous intracellular recordings were obtained, we recorded extra- and intracellular activities during $>100$ seizures. Of these, in three experiments (56 seizures), we observed an increased frequency of spontaneous neuronal firing prior to the seizure and a progressive decrease in the mean firing frequency toward the end of the seizure (Fig. 1). The progressive increase in the neuronal firing prior to seizure was often associated with progressive depolarization of the membrane potential of simultaneously recorded neuron that eventually led to a firing (Fig. 1). The decrease in firing rate during the seizure was related to the presence of prolonged hyperpolarizing, silent periods, which corresponded to the EEG "wave" components of seizures and to a strong depolarization to the level of spike inactivation, associated with paroxysmal depolarizing shifts (PDSs). In the focus of seizure, the high-frequency firing during the PDSs was recorded only in fast-spiking inhibitory interneurons (Timofeev et al. 2002b) and in some fast-rhythmic-bursting neurons (not shown). The increased firing in a large population of neurons recorded at different depths within one cortical column will likely lead to increased $\left[\mathrm{K}^{+}\right]_{\mathrm{o}}$ that should depolarize neighboring neurons due to depolarizing shift in the reversal potential for $\mathrm{K}^{+}$conductances, thus further increasing their firing and leading to the generation of seizures.

\section{Extracellular $\mathrm{K}^{+}$concentration in silent and active states}

We further investigated seizure generation due to increased $\left[\mathrm{K}^{+}\right]_{\mathrm{o}}$ with computational models, starting with the periodic bursting in a single (isolated) PY cells. Based on these results we then study network dynamics.

In normal conditions, random Poisson-distributed input spike trains applied to an isolated PY cell induced asynchronous firing in the $30-$ to $40-\mathrm{Hz}$ frequency range. $\mathrm{K}^{+}$was released into the extracellular space with each spike and was largely taken up by the glial buffering system. The $\mathrm{K}^{+}$pump also prevented $\left[\mathrm{K}^{+}\right]_{\mathrm{o}}$ from growing. It took $\sim 50 \mathrm{~s}$ to reach steady state, where $\left[\mathrm{K}^{+}\right]_{\mathrm{o}}$ in the soma and dendrites were stabilized at $\sim 3-3.5 \mathrm{mM}$ and the concentration of somatic buffered $\mathrm{K}^{+}$, [KB], reached 20-25 mM (Fig. 2). When the 


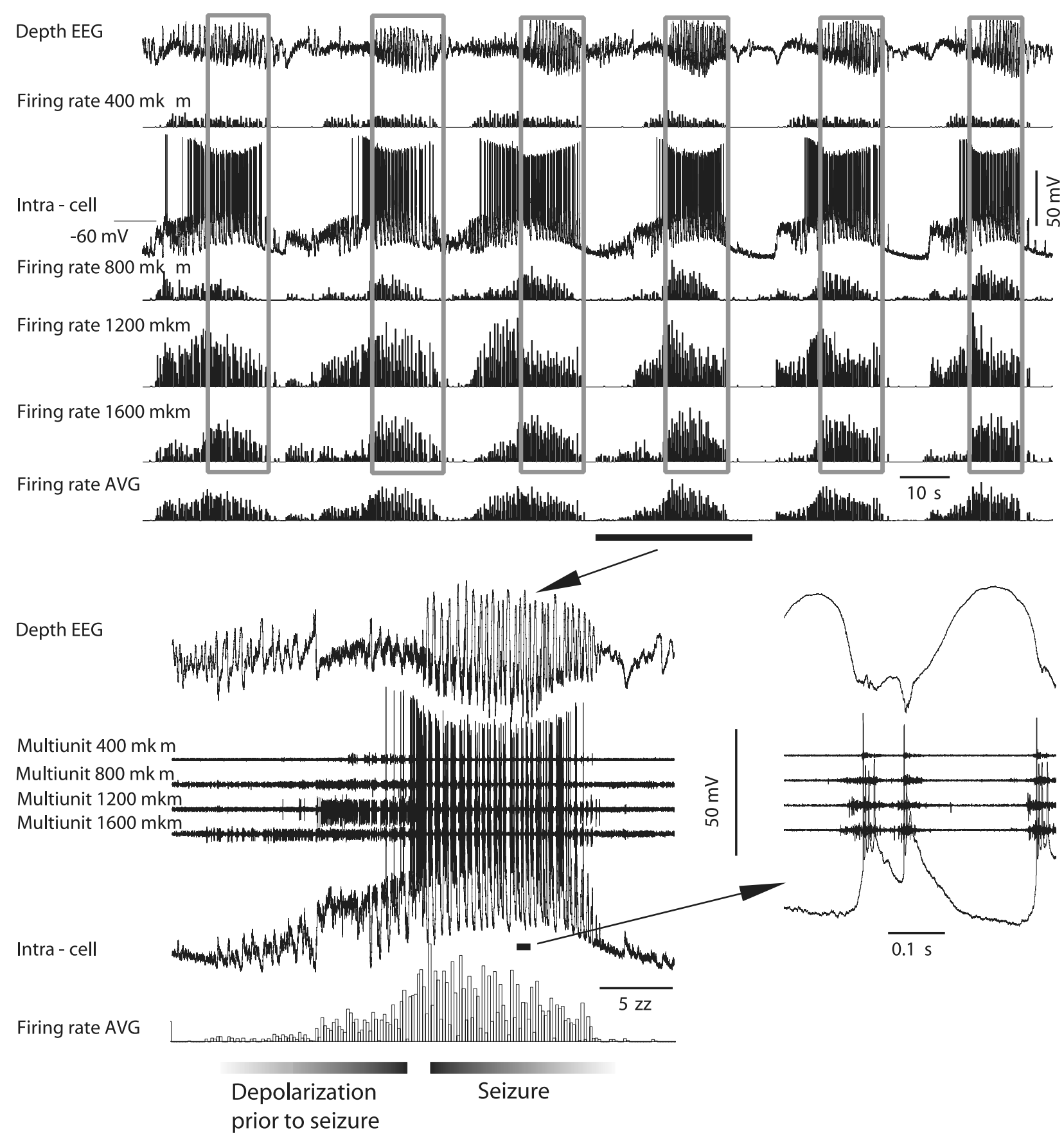

FIG. 1. Progressively increased neuronal firing at the onset of seizures and decreased firing toward the end of seizures. Top: simultaneous field potential and intracellular recordings as well as firing rates obtained from simultaneous multiunit recordings from different cortical depths and averaged firing rates. Seizures are indicated by gray rectangulars. The vertical distance between tips of recording tungsten electrodes was $\sim 400 \mu \mathrm{m}$. The depth of intracellularly recorded neuron estimated from micromanipulator reading was $650 \mu \mathrm{m}$. Bottom left: 1 seizure from top expanded in which examples of multiunit recordings are shown. One spike-wave complex from this seizure is further expanded (right).

external input was removed, the cell remained silent. The release of $\mathrm{K}^{+}$to the extracellular space through $\mathrm{K}^{+}$leak channels was reduced and the steady-state value of $[\mathrm{KB}]$, the potassium bound to the buffer, was much lower $(\sim 10 \mathrm{mM})$; $\left[\mathrm{K}^{+}\right]_{\mathrm{o}}$ in soma and dendrites were slightly lower than in the active state (see Fig. 2, right).

These results show that the glial buffering system implemented in the model can control $\left[\mathrm{K}^{+}\right]_{\mathrm{o}}$ in different neuron states. Because the total capacity of the $\mathrm{K}^{+}$buffer was set to have a concentration of $500 \mathrm{mM}$, it would require a significantly higher frequency of firing before the buffer was saturated.

\section{Effect of external stimulation on extracellular $K^{+}$concentration}

When a long (10 s) DC pulse was applied to the cell, it fired at high frequency and led to a gradual increase in $\left[\mathrm{K}^{+}\right]_{\mathrm{o}}$ (Fig. 3 ). $[\mathrm{KB}]$ reached $\sim 80 \mathrm{mM}$. After the DC stimulus was re- 
A

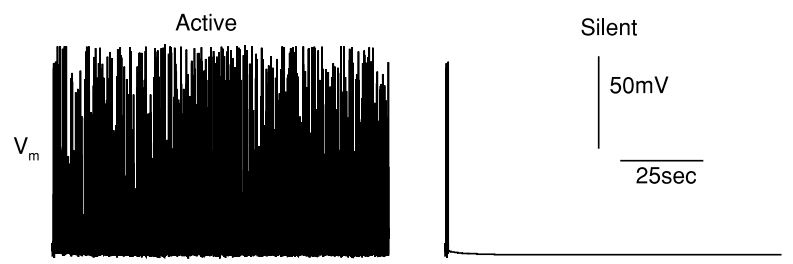

B

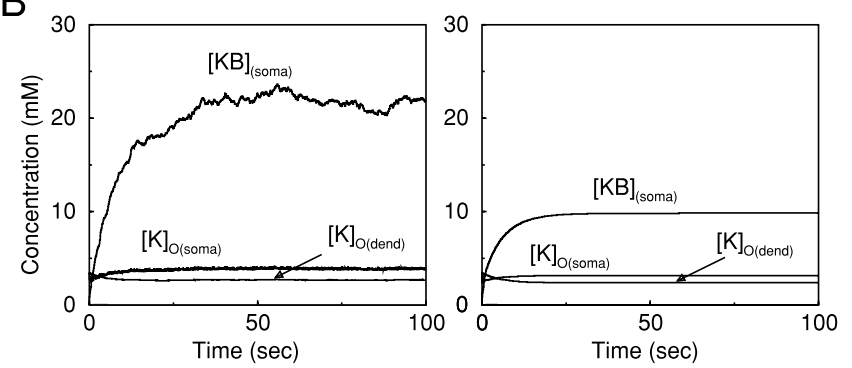

FIG. 2. Silent and active states of a single neuron. A: Poisson distributed random input depolarized single pyramidal (PY) cell that fired randomly. Extracellular $\mathrm{K}^{+}$concentration $\left(\left[\mathrm{K}^{+}\right]_{\mathrm{o}}\right)$ fluctuated $\sim 2.5-3 \mathrm{mM}$ and concentration of $\mathrm{K}^{+}$bound to the buffer $([\mathrm{KB}])$ stabilized at $\sim 25 \mathrm{mM}$. $B$ : silent state with no external stimulation.

moved, the cell did not stop firing immediately but displayed 2.5- to $3.5-\mathrm{Hz}$ oscillations lasting $\sim 10 \mathrm{~s}$, followed by a shorter $(\sim 5 \mathrm{~s})$ period of $10-$ to $15-\mathrm{Hz}$ activity and then by silence. Both $[\mathrm{KB}]$ and $\left[\mathrm{K}^{+}\right]_{\mathrm{o}}$ decayed during the oscillatory state. This decay was mainly due to the $\mathrm{K}^{+}$pump: when the $\mathrm{K}^{+}$pump was blocked just before removing the DC pulse, $\left[\mathrm{K}^{+}\right]_{\mathrm{o}}$ kept growing and the oscillations never stopped (not shown). Reducing the DC pulse amplitude reduced the frequency of firing, the $\left[\mathrm{K}^{+}\right]_{\mathrm{o}}$ was less elevated at the end of stimulation and the duration of the bursting phase was reduced. The minimal frequency of stimulus-induced firing to produce periodic bursting was $\sim 65 \mathrm{~Hz}$. For lower frequencies of firing (induced by stimulations of lower amplitude), the glial buffering and $\mathrm{K}^{+}$ pump were sufficient to restrict the $\left[\mathrm{K}^{+}\right]_{\mathrm{o}}$ increase and prevent oscillations. Note, however, that in this single-cell model $\left[\mathrm{K}^{+}\right]_{\mathrm{o}}$ increased faster during cell firing than it would normally in cortex because $\mathrm{K}^{+}$was confined to the region surrounding a neuron and could not diffuse away.

During the initial phase of oscillations, each burst started with a few $\mathrm{Na}^{+}$spikes followed by spike inactivation and a depolarizing plateau that lasted 50-100 ms (see Fig. 3A, left). Activation of the high-threshold $\mathrm{Ca}^{2+}$ channels increased the intracellular $\mathrm{Ca}^{2+}$ concentration and increased $I_{\mathrm{K}(\mathrm{Ca})}$, which eventually triggered a switch to the hyperpolarized state (Fig. $3 B$, top). During elevated $\left[\mathrm{K}^{+}\right]_{\mathrm{o}}$, the reversal potentials for all $\mathrm{K}^{+}$currents [including $I_{\mathrm{h}}$ (Spain et al. 1987)] were depolarized (Fig. 3A, bottom). The slow membrane potential depolarization after the burst termination eventually activated the persistent sodium current (Fig. 3B, bottom) and led to a new burst. The frequency of bursting was determined by $I_{\mathrm{h}}$ and $I_{\mathrm{K}(\mathrm{Ca})}$, which were the only two currents active during hyperpolarized state (Fig. 3B). Such bursting with spike inactivation is frequently observed during 2- to $3-\mathrm{Hz}$ SW seizures (Neckelmann et al. 1998; Steriade and Contreras 1995, 1998; Steriade et al. 1998a; Timofeev et al. 1998). When $\left[\mathrm{K}^{+}\right]_{\mathrm{o}}$ was partially reduced 5-6 $\mathrm{s}$ later, the high-frequency bursts occurred without spike inac- tivation and the frequency of bursting was increased to $3-4 \mathrm{~Hz}$ (see Fig. 3A, right). During the last phase of oscillation, the bursting was replaced by single spikes or spike doublets occurred at 10-15 Hz. This later form of oscillation resembled "fast-runs" recorded during spike-wave seizures (Steriade et al. 1998a). The transition from low-frequency bursting with many spikes per burst to fast bursting with only few spikes was a result of progressive decrease of $\left[\mathrm{K}^{+}\right]_{\mathrm{o}}$. In the next section, we will show that changing $\left[\mathrm{K}^{+}\right]_{\mathrm{o}}$ from 4 to $5 \mathrm{mM}$ leads to a sequence of bifurcations when the spikes count per burst progressively changes (see Fig. 4).

To determine whether simultaneous depolarization of the $\mathrm{K}^{+}$reversal potentials in the soma and dendrites was required for oscillations, $\left[\mathrm{K}^{+}\right]_{\mathrm{o}}$ was held constant during stimulation either around the dendritic compartment (Fig. 3B, left) or around the soma (Fig. 3B, right). In both cases the slow 2- to $3-\mathrm{Hz}$ paroxysmal oscillations were not observed. Brief $(\sim 2 \mathrm{~s}$ duration) $10-\mathrm{Hz}$ activity occurred in the latter case. This suggests that although elevation of $\left[\mathrm{K}^{+}\right]_{\mathrm{o}}$ in soma and dendrites can affect different conductances, both phenomena are required to initiate and maintain slow periodic oscillations (see following text). We also tested whether the difference in $\left[\mathrm{K}^{+}\right]_{\mathrm{o}}$ between soma and dendrites is critical for the results presented here. Figure $3 E$ presents results of simulations identical to Fig. $3 A$ except that $\mathrm{K}^{+}$diffusion between dendrites and soma was included. It provided nearly identical levels of $\left[\mathrm{K}^{+}\right]_{\mathrm{o}}$ between compartments (see Fig. 3E, bottom) but results (neuron response patterns) stayed the same except that duration of poststimulus oscillations was increased slightly.

When the same DC stimulus was applied to an isolated IN, periodic oscillation was not found after stimulus termination (Fig. $3 D$ ). This is explained by absence of $I_{\mathrm{Na}(\mathrm{p})}$ and reduced $I_{\mathrm{K}(\mathrm{Ca})}\left(g_{\mathrm{K}(\mathrm{Ca})}=0.3 \mathrm{mS} / \mathrm{cm}^{2}\right), I_{\mathrm{Ca}}\left(g_{\mathrm{Ca}}=10 \mu \mathrm{S} / \mathrm{cm}^{2}\right)$, and $I_{\mathrm{h}}$ $\left(g_{\mathrm{h}}=0.05 \mathrm{mS} / \mathrm{cm}^{2}\right)$ conductances in the IN model. Direct increase of the $\left[\mathrm{K}^{+}\right]_{\mathrm{o}}$ led to IN tonic firing (not shown) but bursting was never observed in this model.

\section{Effect of $\left[\mathrm{K}^{+}\right]_{o}$ increase on neuron oscillations}

To better explore the effect of $\left[\mathrm{K}^{+}\right]_{\mathrm{o}}$ on neuron oscillations, we blocked the subsystem updating $\left[\mathrm{K}^{+}\right]_{\mathrm{o}}$ in the model and then increased $\left[\mathrm{K}^{+}\right]_{\mathrm{o}}$ gradually from its baseline level $\left[\mathrm{K}^{+}\right]_{\mathrm{o}}=3$ $\mathrm{mM}$, keeping $\left[\mathrm{K}^{+}\right]_{\mathrm{o}}$ identical around soma and dendrites. Figure $4 \mathrm{~A}$ shows steady-state voltage for nonoscillatory regime $\left(\left[\mathrm{K}^{+}\right]_{\mathrm{o}}<4.3\right.$ $\mathrm{mM}$ ) and the maximum and minimal voltage for periodic solutions $\left(\left[\mathrm{K}^{+}\right]_{\mathrm{o}}>4.3 \mathrm{mM}\right)$. Figure $4 B$ displays $\left[\mathrm{Ca}^{2+}\right]_{\mathrm{i}}$ versus $\left[\mathrm{K}^{+}\right]_{\mathrm{o}}$ on the secant $V_{\mathrm{m}}=0$. The first bifurcation occurs at $\left[\mathrm{K}^{+}\right]_{\mathrm{o}} \sim 4.3 \mathrm{mM}$ where steady-state regime (Fig. 4C, top left) is replaced by periodic firing (Fig. 4C, top right). Near this point each burst was relatively short and included two to three spikes, which was not sufficient to activate $I_{\mathrm{K}(\mathrm{Ca})}$. The inset (Fig. 4B) shows a blow-up of the region where a few bifurcations were found that corresponded to changes in the spike count. In a narrow region $4.85 \mathrm{mM}<\left[\mathrm{K}^{+}\right]_{\mathrm{o}}<4.95 \mathrm{mM}$ long bursts with more than four spikes were observed (Fig. $4 C$, middle left). Starting from $\left[\mathrm{K}^{+}\right]_{\mathrm{o}} \sim 4.95 \mathrm{mM}$, periodic bursting was followed by spike inactivation (Fig. $4 C$, middle right). In Fig. $4 B$, the last oscillatory mode was characterized by the appearance of the upper branch corresponding to the burst termination after a depolarizing plateau. This regime was observed over a large range of $\left[\mathrm{K}^{+}\right]_{\mathrm{o}}$; longer intervals of spike inactivation were observed for higher levels of $\left[\mathrm{K}^{+}\right]_{\mathrm{o}}$ (Fig. 4C, bottom left). Finally, when $\left[\mathrm{K}^{+}\right]_{\mathrm{o}}$ exceeded $\sim 13.5$ 
A
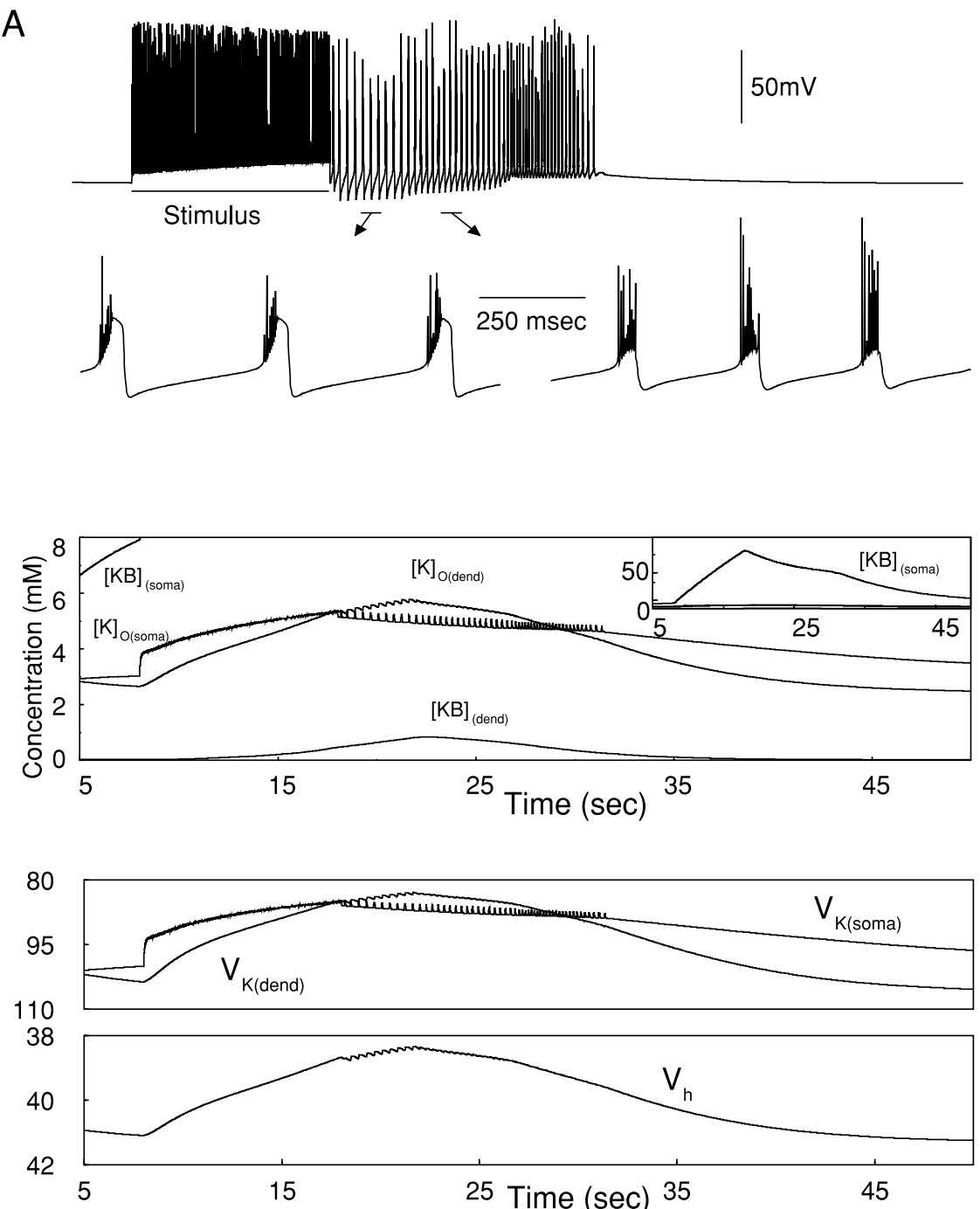

$\mathrm{E}$

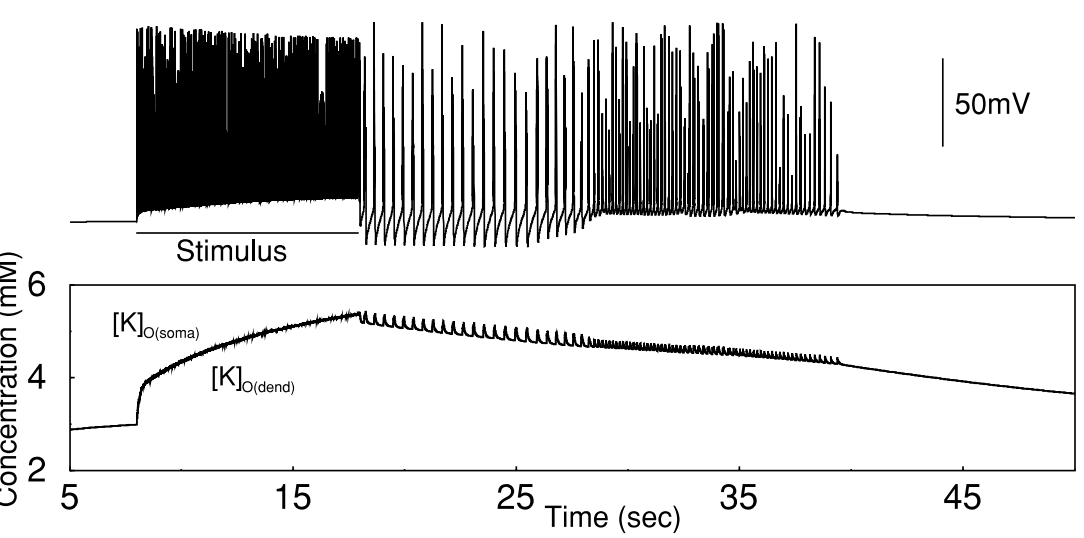

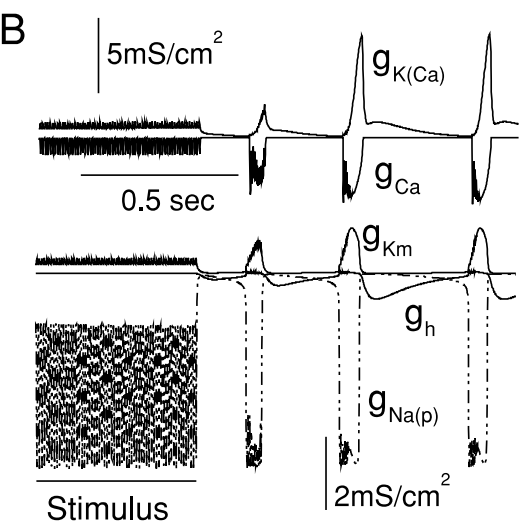

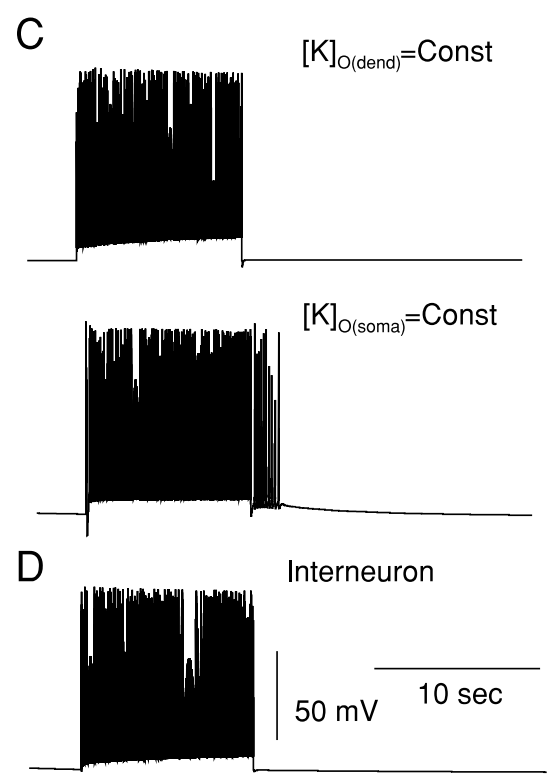

FIG. 3. Periodic activity induced by a current pulse. A: DC pulse $(10 \mathrm{~s}$ in duration) was applied to the silent cell. After high-frequency firing, $\left[\mathrm{K}^{+}\right]_{\mathrm{o}}$ increased and maintained periodic 2- to $3-\mathrm{Hz}$ oscillations in PY neuron lasted about $10 \mathrm{~s}$ after DC pulse was removed. $B$ : time evolution of ionic conductances. $C$ : when $\left[\mathrm{K}^{+}\right]_{\mathrm{o}}$ was increased around somatic (left) or dendritic (right) compartment only, low-frequency oscillations were absent. $D$ : the same stimulus applied to interneuron (IN) was not followed by periodic bursting. $E$ : including $\mathrm{K}^{+}$diffusion between dendrites and soma eliminated difference in $\left[\mathrm{K}^{+}\right]_{\mathrm{o}}$ levels between compartments, but the neuron response patterns remained largely unchanged.

$\mathrm{mM}$, the membrane potential became permanently locked in the depolarized state (Fig. 4C, bottom right). Projections of the phase space to the plane $V_{\mathrm{m}}\left(\left[\mathrm{Ca}^{2+}\right]_{\mathrm{i}}\right)$ for some of these regimes are shown in Fig. $4 D$.

\section{Oscillations induced by $\mathrm{K}^{+}$injection}

To study the relative importance of the $\left[\mathrm{K}^{+}\right]_{\mathrm{o}}$ increase around the soma and dendrites, a fixed amount of $\mathrm{K}^{+}$was 

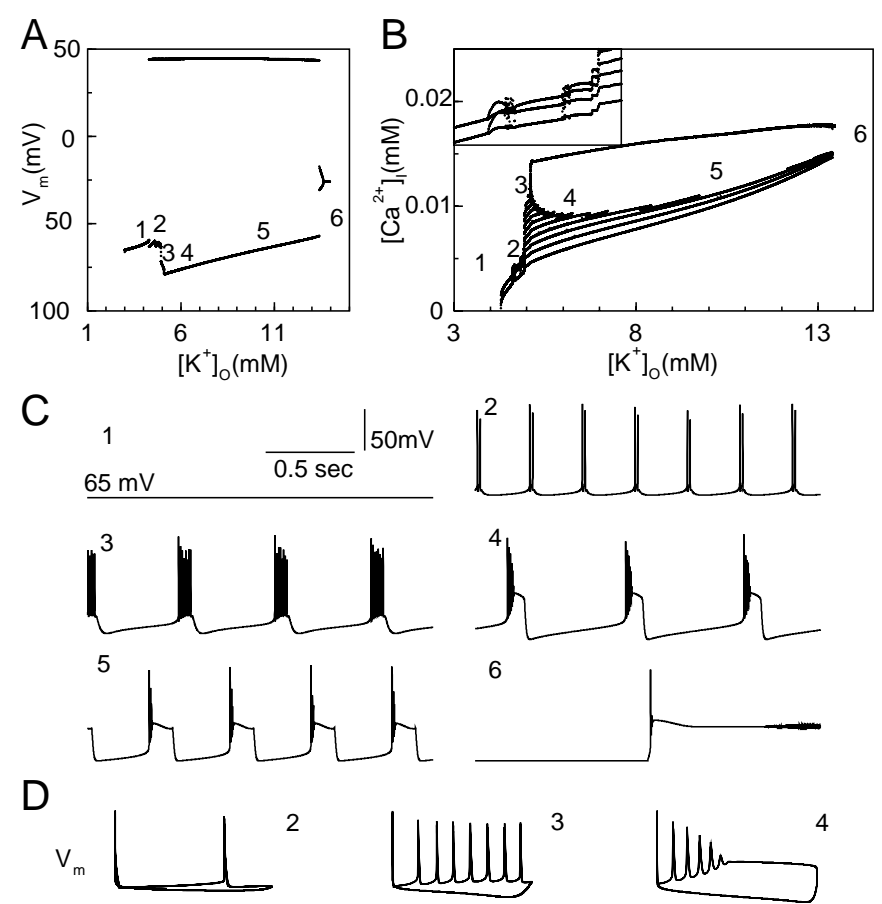

$\left[\mathrm{Ca}^{2+}\right]_{1}$

$\left[\mathrm{Ca}^{2+}\right]$
6
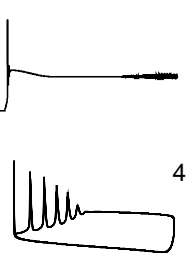

$\left[\mathrm{Ca}^{2+}\right]_{1}$

FIG. 4. Effect of $\left[\mathrm{K}^{+}\right]_{\mathrm{o}}$ increase on neuron oscillations. A: bifurcation diagram (stable attractors) shows steady-state voltage for nonoscillatory regime $\left(\left[\mathrm{K}^{+}\right]_{\mathrm{o}}<4.3 \mathrm{mM}\right)$ and the maximum and minimal voltage for periodic solutions $\left(\left[\mathrm{K}^{+}\right]_{\mathrm{o}}>4.3 \mathrm{mM}\right) . B:\left[\mathrm{Ca}^{2+}\right]_{\mathrm{i}}$ on the secant $V_{\mathrm{m}}=0$ for different levels of $\left[\mathrm{K}^{+}\right]_{0}$. Appearance of the upper branch at $\left[\mathrm{K}^{+}\right]_{\mathrm{o}}>4.95 \mathrm{mM}$ indicates regimes with spike inactivation. Inset: interval $4.5 \mathrm{mM}<\left[\mathrm{K}^{+}\right]_{\mathrm{o}}<5 \mathrm{mM}$. C: examples of oscillatory regimes corresponding to $\left[\mathrm{K}^{+}\right]_{0}$ values marked by numbers $1\left(\left[\mathrm{~K}^{+}\right]_{\mathrm{o}}=3.5 \mathrm{mM}\right), 2\left(\left[\mathrm{~K}^{+}\right]_{\mathrm{o}}=4.5 \mathrm{mM}\right), 3\left(\left[\mathrm{~K}^{+}\right]_{\mathrm{o}}=4.9 \mathrm{mM}\right), 4$ $\left(\left[\mathrm{K}^{+}\right]_{\mathrm{o}}=6 \mathrm{mM}\right), 5\left(\left[\mathrm{~K}^{+}\right]_{\mathrm{o}}=10 \mathrm{mM}\right)$, and $6\left(\left[\mathrm{~K}^{+}\right]_{\mathrm{o}}=14 \mathrm{mM}\right)$ in $A$ and $B$. $D$ : phase portraits $V_{\mathrm{m}}\left(\left[\mathrm{Ca}^{2+}\right]_{\mathrm{i}}\right)$ for oscillatory regimes shown above.

directly injected into the extracellular space during the silent state of the neuron (Fig. 5). Increase of $\left[\mathrm{K}^{+}\right]_{\mathrm{o}}$ alone around the soma was not sufficient to induce oscillations (Fig. 5A). Note that $\left[\mathrm{K}^{+}\right]_{\mathrm{o}}$ at first increased significantly but then rapidly decayed to a lower steady-state level. This decay was due to the $\mathrm{K}^{+}$glial buffering and occurred simultaneously with increase in $[\mathrm{KB}]$. When $\left[\mathrm{K}^{+}\right]_{\mathrm{o}}$ was elevated both around the soma and dendrites (Fig. $5 B$ ), the previously described low-frequency bursting with spike inactivation occurred. Further increase of $\left[\mathrm{K}^{+}\right]_{\mathrm{o}}$ around dendrites led to bursting without spikes inactivation (Fig. $5 C$ ) and finally to fast $10-$ to $15-\mathrm{Hz}$ oscillations (Fig. $5 D$ ). When $\left[\mathrm{K}^{+}\right]_{\mathrm{o}}$ was increased around dendrites to the same level as in Fig. $5 B$ but with a less significant increase in soma, only fast 10 - to $15-\mathrm{Hz}$ oscillations were observed (Fig. $5 E$ ). These results are summarized at Fig. $5 F$ where regions of different behavior are shown. Slow $(<4 \mathrm{~Hz})$ bursting with spike inactivation was observed over a wide range of $\left[\mathrm{K}^{+}\right]_{0}$ including the line $\left[\mathrm{K}^{+}\right]_{\mathrm{o} \text { (soma }}=\left[\mathrm{K}^{+}\right]_{\mathrm{o}(\text { dend) }}$. Note that the region of bursting without spike inactivation, which was relatively small in the model with identical levels of $\left[\mathrm{K}^{+}\right]_{\mathrm{o}}$ around soma and dendrites $\left(4.3 \mathrm{mM}<\left[\mathrm{K}^{+}\right]_{\mathrm{o}}<4.95 \mathrm{mM}\right.$; see, Fig. 4 ), was now extended to much larger values of $\left[\mathrm{K}^{+}\right]_{\mathrm{o}}$; however, $\left[\mathrm{K}^{+}\right]_{\mathrm{o}(\text { soma) }}$ had to be less than $\left[\mathrm{K}^{+}\right]_{\mathrm{o}(\mathrm{dend})}$ for this to occur.

\section{Effects of intrinsic conductances on $\mathrm{K}^{+}$-induced oscillations}

High-threshold $\mathrm{Ca}^{2+}$ and persistent $\mathrm{Na}^{+}$currents were important in creating periodic bursting after a $\left[\mathrm{K}^{+}\right]_{\mathrm{O}}$ increase (Fig. 6). After oscillations were induced by long DC stimulation, as described in the preceding text, a sufficiently high maximal conductances for $I_{\mathrm{Na}(\mathrm{p})}$ and $I_{\mathrm{Ca}}$ were required to maintain periodic bursting. On the $g_{\mathrm{Ca}}\left(g_{\mathrm{Na}(\mathrm{p})}\right)$ plane (see Fig. $6 A$, left), the region for bursting was bounded by two curves. Below the bottom curve no oscillations were observed. Above the top curve strong $I_{\mathrm{Ca}}$ and/or $I_{\mathrm{Na}(\mathrm{p})}$ induced a transient "lock" of the membrane potential in a depolarized state (spike inactivation). All these regimes are illustrated in Fig. $6 C$, where the maximal change of $\left[\mathrm{Ca}^{2+}\right]_{\mathrm{i}}$ during a burst duration is plotted for a cell held at a constant elevated level of $\left[\mathrm{K}^{+}\right]_{\mathrm{o}}=5.5 \mathrm{mM}$ (note that Fig. $4 B$ shows $\left[\mathrm{Ca}^{2+}\right]_{\mathrm{i}}$ change as a function of $\left.\left[\mathrm{K}^{+}\right]_{\mathrm{O}}\right)$. Increase of $I_{\mathrm{Na}(\mathrm{p})}$ and/or $I_{\mathrm{Ca}}$ led to bursts with more spikes producing higher $\left[\mathrm{Ca}^{2+}\right]_{\mathrm{i}}$ increase. A transient region $\mathrm{B}$ between lower plateau $\mathrm{A}$ and upper plateau $\mathrm{C}$ in Fig. $6 \mathrm{C}$ corresponds to the area between two curves in the Fig. $6 \mathrm{~A}$ (left) where the number of spikes progressively increases as $g_{\text {Ca }}$ and/or $g_{\mathrm{Na}(\mathrm{p})}$ changes; region C corresponds to long bursts with spike inactivation. Finally, in region D, the membrane potential was permanently "locked" in a depolarized state (see Fig. $4 C$, bottom right), which occurred for high $g_{\mathrm{Na}(\mathrm{p})}$ and relatively low $g_{\mathrm{Ca}}$. The latter condition ensured weak $I_{\mathrm{K}(\mathrm{Ca})}$ activation. Examples of different firing patterns are shown in Fig. $6 B$.

The conductance for $I_{\mathrm{K}(\mathrm{Ca})}$ significantly affected both the frequency and duration of poststimulus oscillations (Fig. 6A, right). When $g_{\mathrm{K}(\mathrm{Ca})}$ was below $\sim 2 \mathrm{mS} / \mathrm{cm}^{2}$ only fast long-lasting oscillations were observed. For higher conductances $2-$ to $3-\mathrm{Hz}$ periodic bursting was found. The frequency increased slightly for $g_{\mathrm{K}(\mathrm{Ca})}>5$ $\mathrm{mS} / \mathrm{cm}^{2}$, which was primary the result of a reduced burst duration. Stronger $I_{\mathrm{K}(\mathrm{Ca})}$ was more effective in terminating the depolarized plateau, so less $\mathrm{Ca}^{2+}$ entered during the depolarized state and repolarization from a hyperpolarized state was also faster.

Among all the currents, $I_{\mathrm{h}}$ was most effective in controlling the frequency of oscillations. Reduction of the $g_{\mathrm{h}}$ reduced the frequency to $\sim 1 \mathrm{~Hz}$ and then eliminated bursting (Fig. $6 D$, left). This is consistent with the importance of $I_{\mathrm{h}}$ in maintaining paroxysmal oscillations as proposed previously (Timofeev et al. 2002a). Increase of the maximal conductances for $I_{\mathrm{Na}(\mathrm{p})}$ and $I_{\mathrm{Km}}$ had the opposite effect on frequency (Fig. 6D, middle and right). Changing maximal conductance for $I_{\mathrm{Ca}}$ had a relatively weak effect on the frequency, although it had to be above certain limit to maintain bursting. This limit depended on the maximal con-

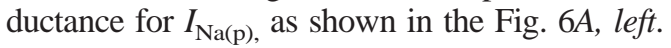

\section{Role of $\mathrm{K}^{+}$pump and glial buffering}

Results with single-cell simulations suggest that elevated $\left[\mathrm{K}^{+}\right]_{\mathrm{o}}$ might also be important for network oscillations. When $\left[\mathrm{K}^{+}\right]_{\mathrm{o}}$ was sufficiently elevated, periodic bursting was found, which resembled oscillations observed during SW seizure in vivo. Two different mechanisms- $\mathrm{K}^{+}$pump and glial buffering-controlled $\left[\mathrm{K}^{+}\right]_{\mathrm{o}}$ in our model. We tested them by separately blocking each system. Figure $7 A$ shows cell activity when glial buffering was blocked. Immediately following the block of the glial buffer (Fig. 7A), the asynchronous firing maintained by random input (see Fig. 2, left) was replaced by periodic $\sim 2.5-\mathrm{Hz}$ bursting with spike inactivation. $\left[\mathrm{K}^{+}\right]_{\mathrm{o}}$ con- 
A

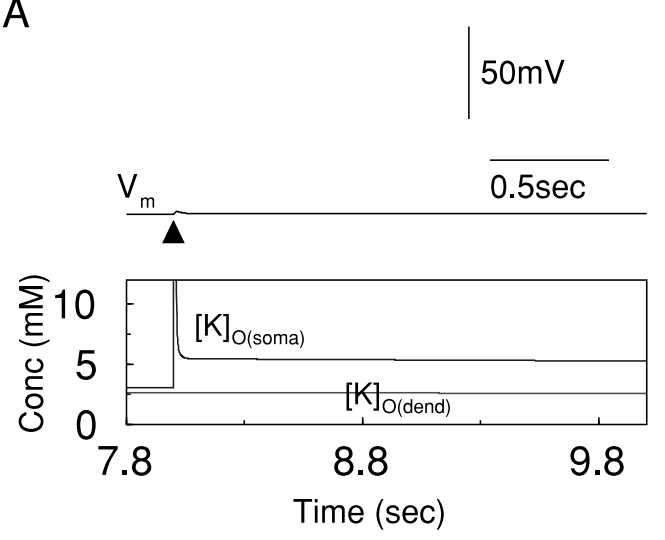

C
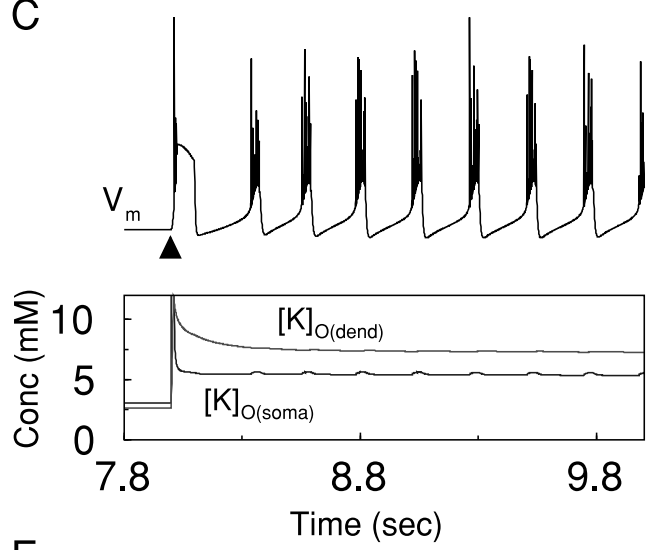

E
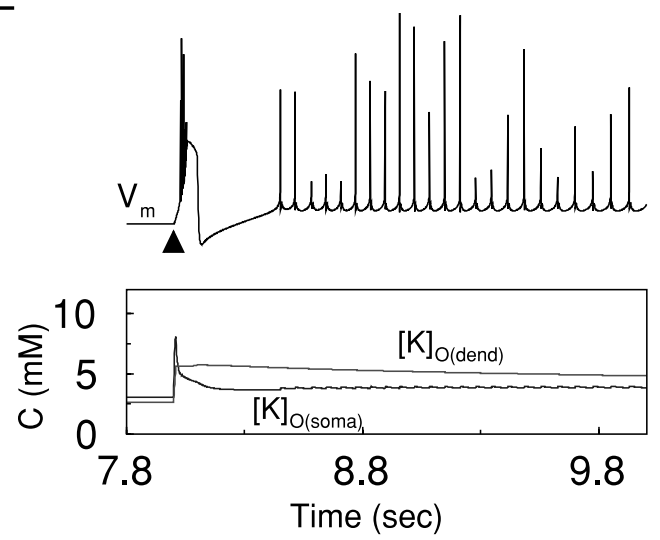

B
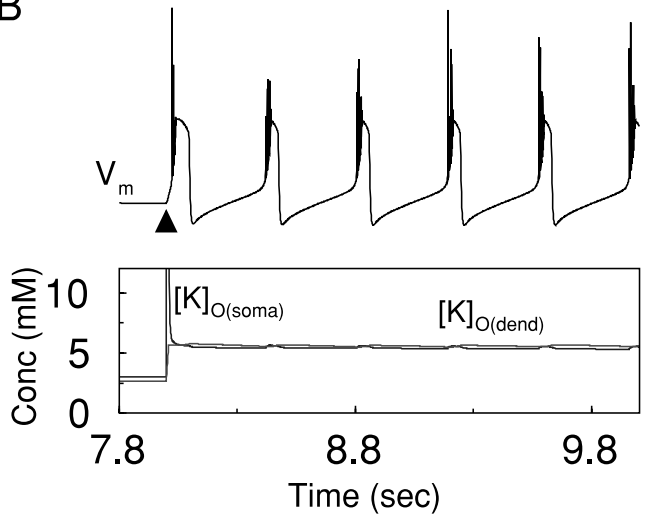

D
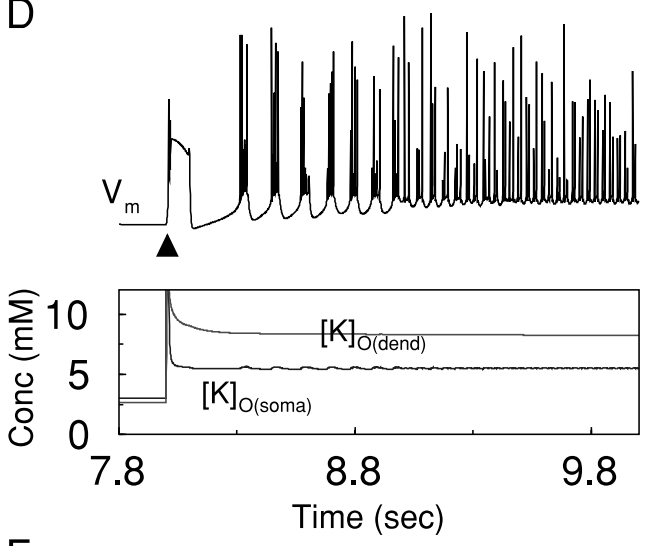

F

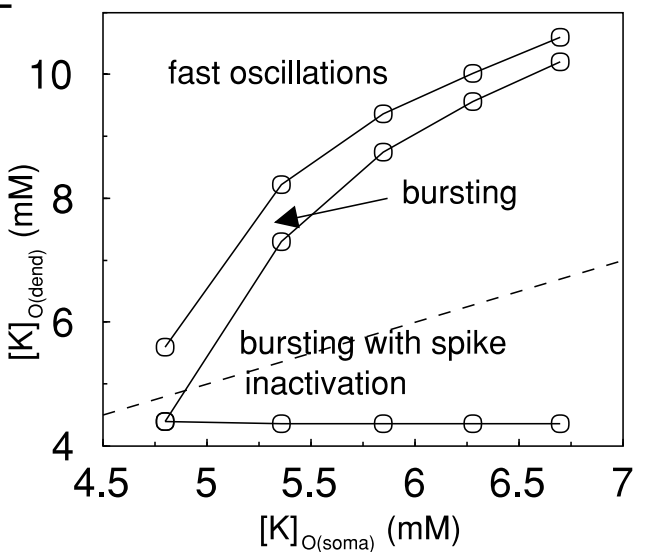

FIG. 5. Oscillations induced by $\left[\mathrm{K}^{+}\right]_{\mathrm{o}}$ injection. $\left[\mathrm{K}^{+}\right]_{\mathrm{o}}$ increase both around dendrites and soma was required to maintain 2 - to $3-\mathrm{Hz}$ activity. $A-D$ : when $\left[\mathrm{K}^{+}\right]_{\mathrm{o}}$ around soma was set to $\sim 5.5 \mathrm{mM}, 5.5-8 \mathrm{mM}$ range of $\left[\mathrm{K}^{+}\right]_{\mathrm{o}}$ in the dendrites was required to initiate oscillations. $E$ : insufficient increase of $\left[\mathrm{K}^{+}\right]_{\mathrm{o}}$ around soma prevented self-sustained oscillations. $F$ : periodic 2- to 3-Hz bursting with spike inactivation (see, e.g., $B$ ) was observed in the large region including $\left[\mathrm{K}^{+}\right]_{\mathrm{o}(\text { soma })}=\left[\mathrm{K}^{+}\right]_{\mathrm{o}(\mathrm{dend})}$ line $(---)$.

tinued to increase slowly during the oscillatory phase and after $\sim 15 \mathrm{~s}$ the oscillations disappeared with the membrane potential permanently "locked" at a depolarized level. The $\mathrm{K}^{+}$ reversal potential increased to a point that $I_{\mathrm{K}(\mathrm{Ca})}$ became ineffective in terminating the depolarized state.

Blocking the $\mathrm{K}^{+}$pump in a single cell had a less dramatic effect but eventually led to bursting (Fig. $7 B$ ). In the presence of random input, this bursting was irregular and occurred in a broad 4- to $20-\mathrm{Hz}$ range. Periods of faster oscillations were interrupted by slower rhythms in the 4 - to $7-\mathrm{Hz}$ range. $\left[\mathrm{K}^{+}\right]_{\mathrm{o}}$ was increased both around the dendrites and in the soma; however, $\left[\mathrm{K}^{+}\right]_{\mathrm{o} \text { (soma) }}$ was saturated at a noticeably lower level.
Based on the diagram shown in Fig. $5 F$, we expected that the $\left[\mathrm{K}^{+}\right]_{\mathrm{o}(\text { soma) }}$ increase was insufficient by itself to induce lowfrequency oscillations with spike inactivation. When external input was removed at $t=30 \mathrm{~s}$, the oscillation continued and become more regular (not shown). Later we will show that in a network of PY cells, blocking $\mathrm{K}^{+}$pump can induce paroxysmal low-frequency bursting.

\section{Stimulus-induced paroxysmal oscillations in the cortical network}

To study the properties of $\left[\mathrm{K}^{+}\right]_{\mathrm{o}}$-dependent oscillations in a population of cortical cells, a two-layer network model includ- 
ing $100 \mathrm{PY}$ cells and 25 inhibitory interneurons (INs) was simulated without lateral diffusion of $\mathrm{K}^{+}$(Fig. 8A). All cells were identical except that $I_{\mathrm{h}}$ was included only in a small
(10\%) randomly selected group of PY neurons (Timofeev et al. 2002a). Without random excitatory stimulation the background state was silent. A DC pulse applied to cells 30-50 induced

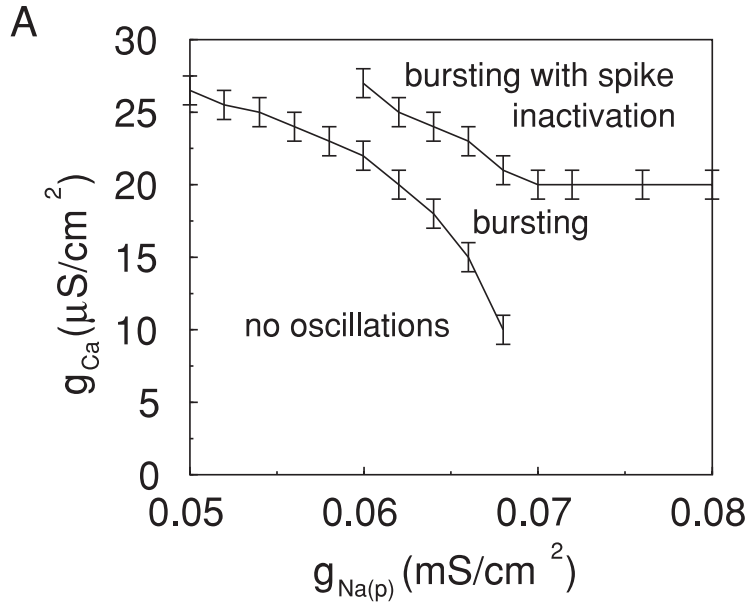

B
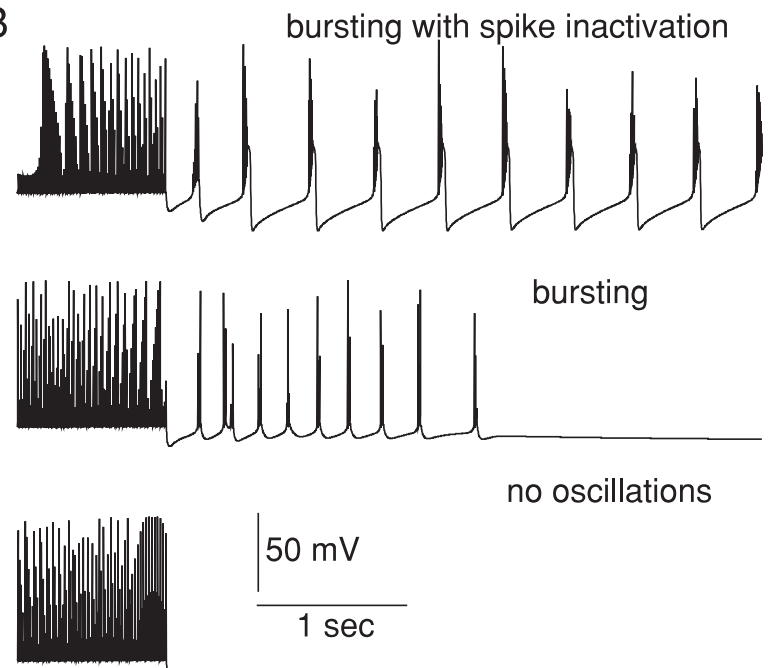

$50 \mathrm{mV}$

$1 \mathrm{sec}$

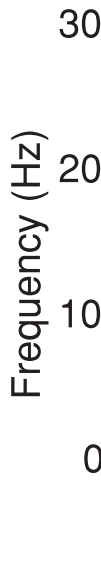

30

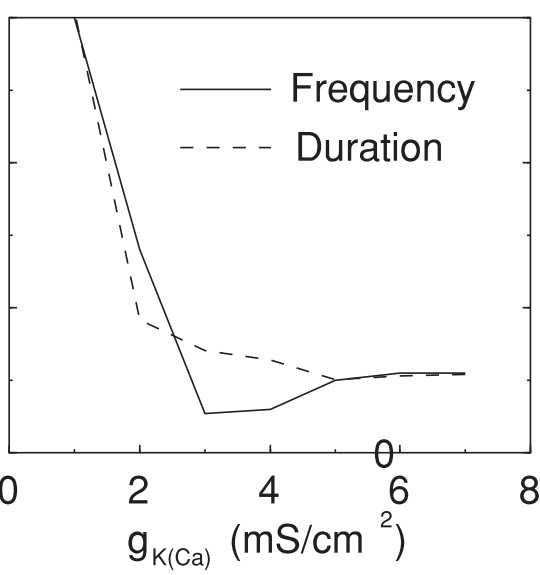

C

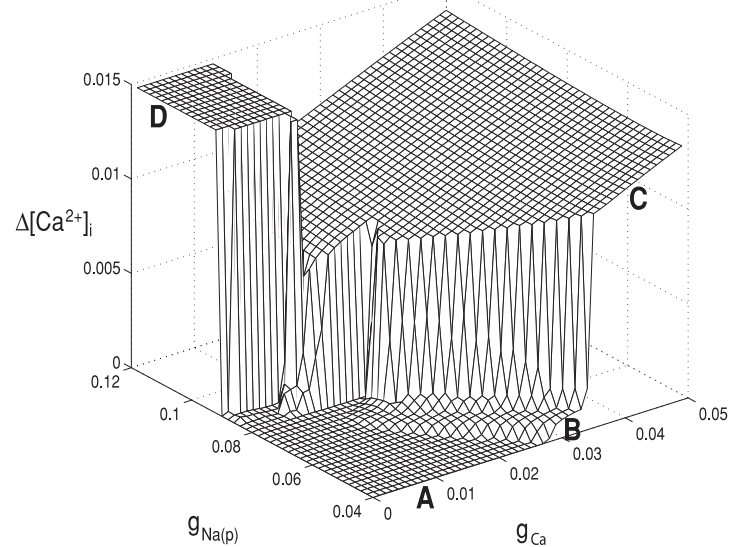

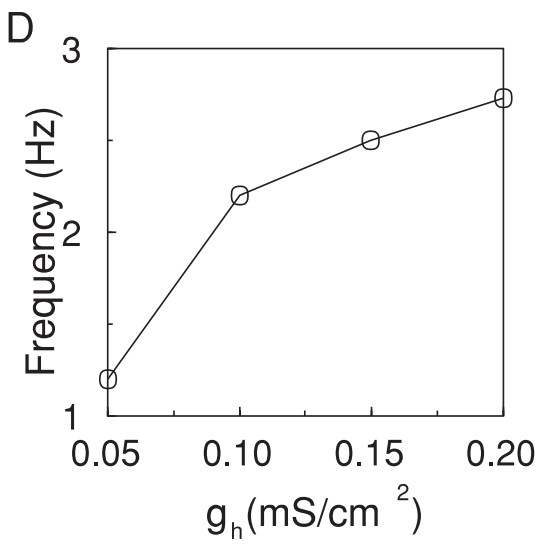
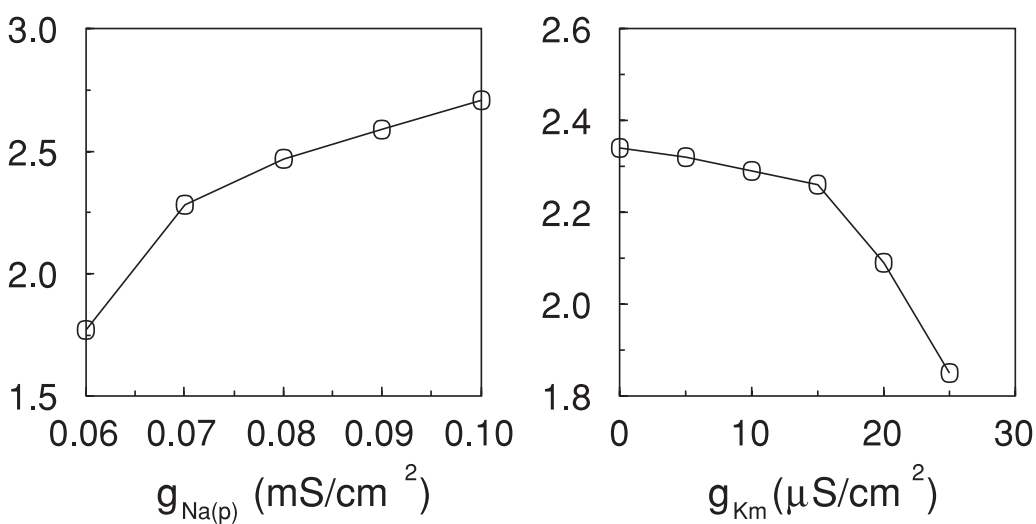

FIG. 6. Effect of intrinsic conductances on neuron oscillations. $A$ : increase of $\left[\mathrm{K}^{+}\right]_{\mathrm{o}}$ during DC stimulation led to oscillations. Sufficiently high levels of persistent $\mathrm{Na}^{+}$and high-threshold $\mathrm{Ca}^{2+}$ conductances were required to maintain periodic bursting (top left). Increase of $\mathrm{Ca}^{2+}$-dependent $\mathrm{K}^{+}$current reduced both duration and frequency of oscillations (top right). B: examples of PY oscillations corresponding to different regimes indicated in $A$, left. $C:\left[\mathrm{Ca}^{2+}\right]_{\mathrm{i}}$ increase during a burst as a function of parameters $g_{\mathrm{Na}(\mathrm{p})}$ and $g_{\mathrm{Ca}}$ for a cell hold at a constant level of $\left[\mathrm{K}^{+}\right]_{\mathrm{o}}(5.5 \mathrm{mM})$. Longer bursts (more spikes or spike inactivation) produced higher $\left[\mathrm{Ca}^{2+}\right]_{i}$ change. Four different regions can be selected: A, no oscillations; B, bursting; $\mathrm{C}$, bursting with spike inactivation; $\mathrm{D}$, membrane potential "lock" in depolarized state. $D$ : effect of the intrinsic conductances on frequency of oscillations. The most significant frequency changes $(1-3 \mathrm{~Hz})$ occurred with variations of the $I_{\mathrm{h}}$ maximal conductance. 
A

No Glial Accumulation
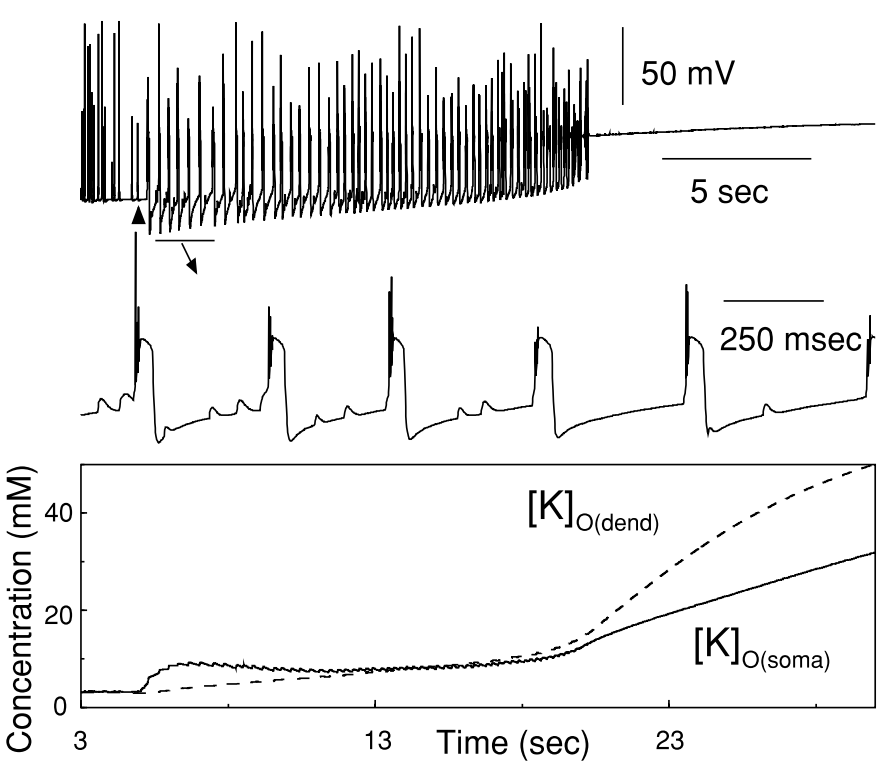

B
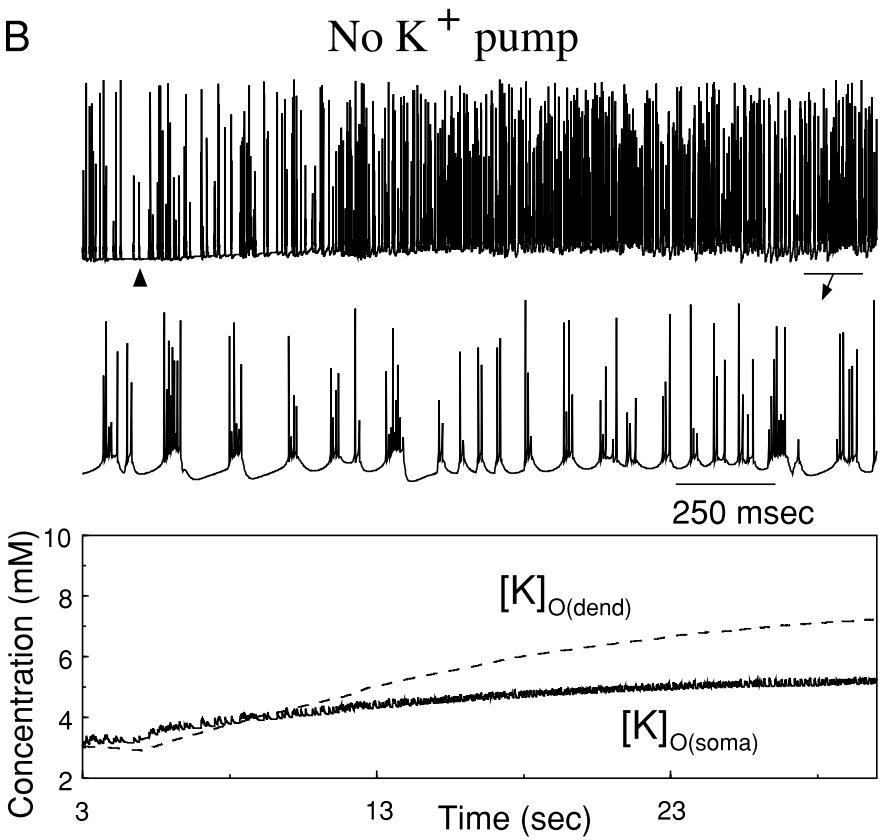

FIG. 7. Effect of glial buffering and $\mathrm{K}^{+}$pump on a neuron activity. A: blocking glial uptake system transformed "normal" random firing maintained by random external stimulation into periodic bursting and eventually led to permanent spike inactivation. $B$ : after block of $\mathrm{K}^{+}$pump, $\left[\mathrm{K}^{+}\right]_{\mathrm{o}}$ increased and led to fast bursting.

high-frequency firing leading to the elevation of $\left[\mathrm{K}^{+}\right]_{\mathrm{o}}$. When the DC stimulation was removed after $30 \mathrm{~s}$, the network continued to oscillate at $\sim 3 \mathrm{~Hz}$. This low-frequency bursting had the same nature as oscillations previously described in an isolated PY cell. Starting $\sim 10 \mathrm{~s}$ after the beginning of stimulation, the neurons outside the region of high $\left[\mathrm{K}^{+}\right]_{\mathrm{o}}$ also displayed periodic bursting. Their activity was mediated by synaptic input from the overexcited region.

When the same simulation was repeated including lateral diffusion of $\mathrm{K}^{+}$(between PY cells), the results were different (Fig. $8 B$ ). Increase of $\left[\mathrm{K}^{+}\right]_{\mathrm{o}}$ within the region of DC stimulation created diffusion of $\mathrm{K}^{+}$to the neighboring regions, so almost all PY cells in the network oscillated starting from $\sim 2$ s after DC stimulation. One hundred percent of the cells displayed bursting after the stimulus was removed at $t=$ $38 \mathrm{~s}$; these oscillations were well synchronized across population. PY cells inside region of DC stimulation typically showed bursts with spike inactivation. The cells outside this region displayed high-frequency bursts without spike inactivation (see Fig, 8B, bottom). Each cycle of poststimulus oscillations was started in a small group of cells (numbers $50-60)$. These cells were located near the region of DC stimulation where $\left[\mathrm{K}^{+}\right]_{\mathrm{o}}$ was significantly increased; a few of these cells included $I_{\mathrm{h}}$ (these cells were slightly depolarized and could be identified at the graph by darker traces). In contrast to the model without diffusion, the oscillations lasted only $\sim 15 \mathrm{~s}$ after removing $\mathrm{DC}$ stimulation. In the model with diffusion, a larger subpopulation of "glial cells" was effectively involved in accommodation of excessive $\left[\mathrm{K}^{+}\right]_{\mathrm{o}}$; its level progressively reduced both in the soma and dendrites until the oscillations could no longer be sustained (see Fig. 8B, middle). Thus lateral $\mathrm{K}^{+}$diffusion may reduce the duration of paroxysmal bursting. $\mathrm{K}^{+}$diffusion between compartments maintained identical levels of $\left[\mathrm{K}^{+}\right]_{\mathrm{o}}$ around soma and dendrites.
Once started the oscillation propagated in both directions with a velocity of $\sim 300$ cells/s. We studied the effect of $\mathrm{K}^{+}$ diffusion on the velocity of burst propagation but could not find any significant velocity changes in a range of $D=0$ to $D=1.2$ $10^{-5} \mathrm{~cm}^{2} / \mathrm{s}$. Lateral $\mathrm{K}^{+}$diffusion promoted bursting by depolarizing neurons located outside the area of direct stimulation; however, this had only minimal effect of the burst velocity. Parameters controlling burst velocity in the model were maximal conductances for excitatory and inhibitory synapses. In agreement with previous works, an increase of lateral excitation between PY neurons increased velocity while increase of inhibitory feedback through IN slowed down propagation (see, e.g., Bazhenov et al. 2002; Compte et al. 2003; Golomb and Ermentrout 2001) .

To test effect of NMDA currents, we repeated simulations without NMDA conductances. In all cases, after blocking NMDA currents network bursting persisted with only minor changes in shape or duration as long as $\left[\mathrm{K}^{+}\right]_{\mathrm{o}}$ was elevated to the same level. Because the presence on NMDA receptors increased the frequency of firing during high-frequency stimulations, longer stimulation times were required to reach the same level of $\left[\mathrm{K}^{+}\right]_{\mathrm{o}}$. Thus to obtain (after NMDA blocking), a response identical to the one shown in the Fig. 8, the duration of DC stimulation had to be increased from 20 to $40 \mathrm{~s}$.

We compared responses found in the 100-PY-25-IN cell network with the larger networks and networks with different synaptic footprints. Our simulations show that doubling or halving the number of neurons in our model network while keeping the same number of synaptic neighbors did not change results. Effect of the footprint change in shown in the Fig. $8 C$ presenting results of 300-PY-75-IN network simulations. In those cells (numbers 160-220) where external stimulation was applied, the oscillations were determined primarily by their intrinsic properties and by the level of $\left[\mathrm{K}^{+}\right]_{\mathrm{o}}$ and therefore were identical to activity in the 


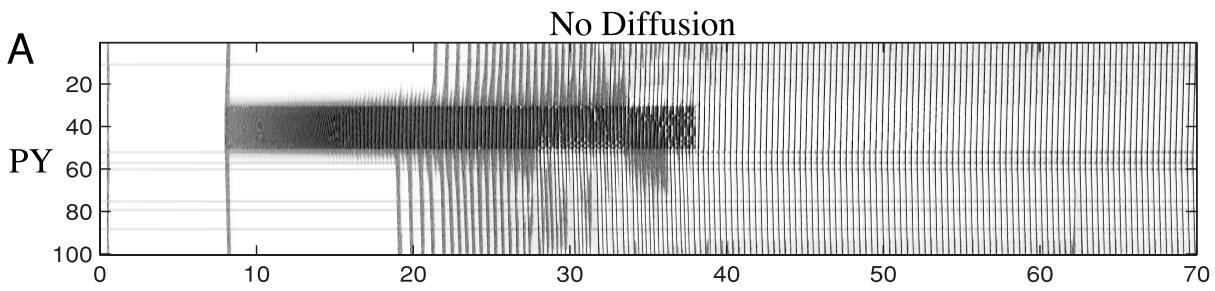

Diffusion
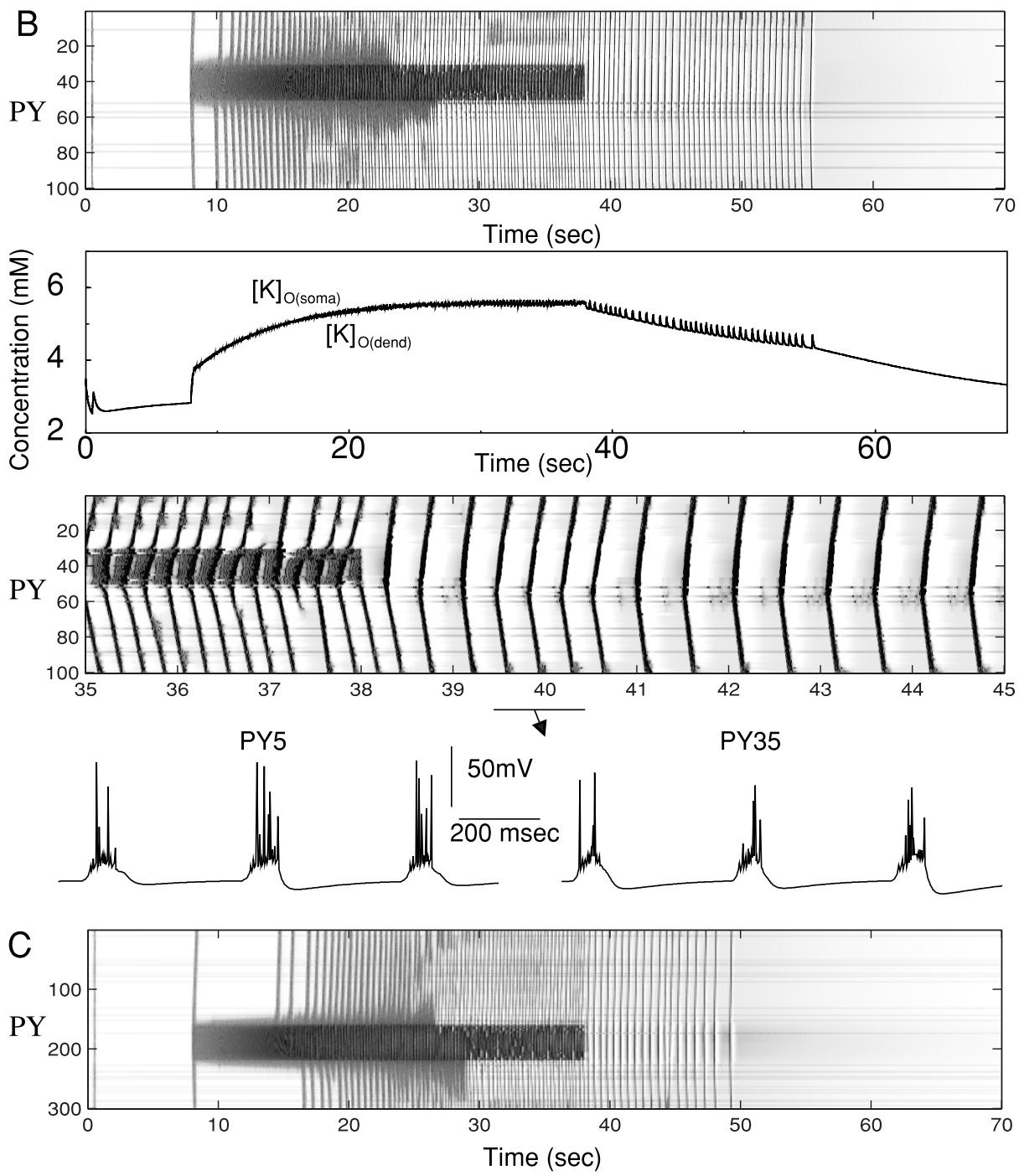

FIG. 8. Network oscillations following DC stimulation. A group of cells (numbers 30-50) was stimulated by DC pulse that induced highfrequency firing. $A$ : after stimulus termination (at $t=38 \mathrm{~s}$ ), the oscillations lasted continuously. $B$ : when lateral (between cells) diffusion of $\mathrm{K}^{+}$was introduced, oscillations were terminated $\sim 15 \mathrm{~s}$ after stimulus termination. $\mathrm{K}^{+}$ diffusion between compartments maintained identical levels of $\left[\mathrm{K}^{+}\right]_{\mathrm{o}}$ around soma and around dendrites. Bottom: $\left[\mathrm{K}^{+}\right]_{\mathrm{o}}$ evolution for neurons 5 and 35 is shown. $C$ : oscillation in a larger network with 300 PY and 75 IN neurons. Connections fan out was \pm 15 cells for AMPA and NMDA mediated PY-PY synapses; \pm 3 cell for AMPA- and $N$-methyl-D-aspartate (NMDA)mediated PY-IN synapses; \pm 15 cells for $\mathrm{GABA}_{\mathrm{A}}$ mediated IN-PY synapses. equivalent group of cells in the smaller network (Fig. 8B). Neurons in the rest of the network were driven by synaptic inputs and $\mathrm{K}^{+}$diffusion; all neurons in the network became involved in periodic bursting which continued for $\sim 10 \mathrm{~s}$ after stimulus termination.

\section{Effect of inhibition on network oscillations}

In the simulations shown in Fig. 9, random network activity was induced by Poisson-distributed spike trains delivered to all PY cells as in the experiments with isolated PY neuron. To compensate for the external stimulation, the strength of synaptic coupling between PY neurons was reduced from 0.15 to $0.115 \mu \mathrm{S}$. In control conditions, the network displayed random firing with the level of $\left[\mathrm{K}^{+}\right]_{\mathrm{o}}$ oscillating around $3 \mathrm{mM}$, which was identical outside the soma and dendrites (see Fig. 9A). When all GABAergic synapses were blocked at $t=5 \mathrm{~s}$, increase of firing in many PY neurons led to the gradual increase of $\left[\mathrm{K}^{+}\right]_{\mathrm{o}}$ (Fig. $9 B$ ). After $\sim 20 \mathrm{~s}$, the system started to display spontaneous bursting at progressively increasing frequency, which stabilized at $2-3 \mathrm{~Hz}$ after $\sim 45 \mathrm{~s}$. The periodic bursting was typically initiated in a group of cells with $I_{\mathrm{h}}$ (cells 55-60).

We also tested networks where inhibition was removed in only a small group of neurons (cells 30-50). In simulations with lateral PY-PY diffusion, localized disinhibition produced no noticeable effect (data not shown). Excessive firing in a small group of PY cells increased $\mathrm{K}^{+}$concentration in adjacent 
A
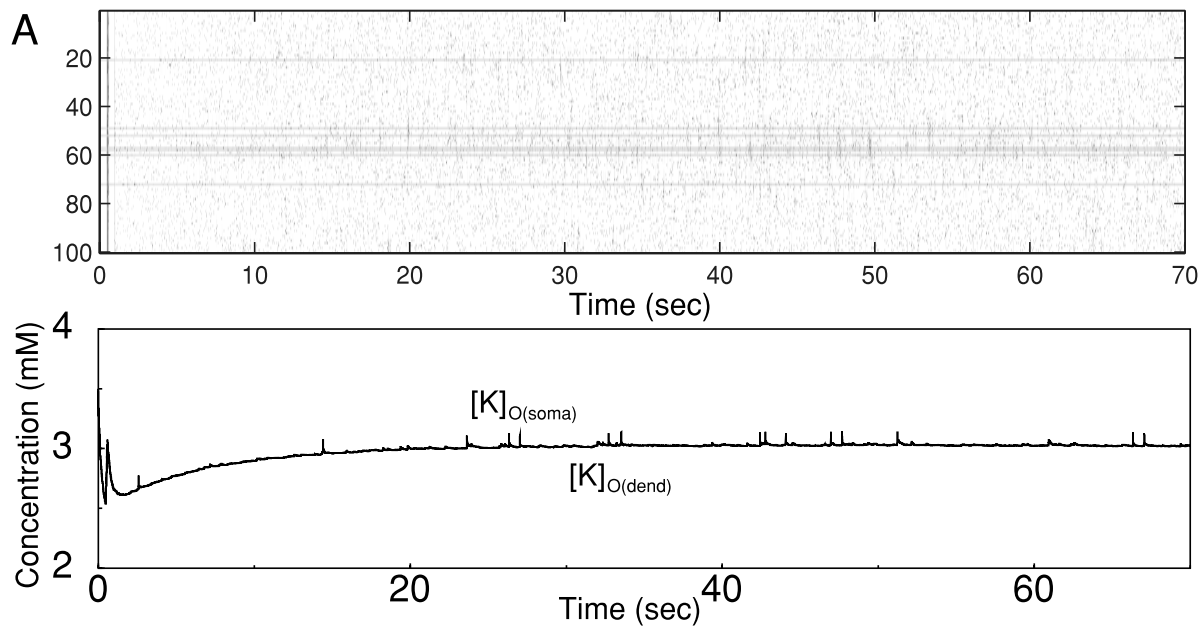

B

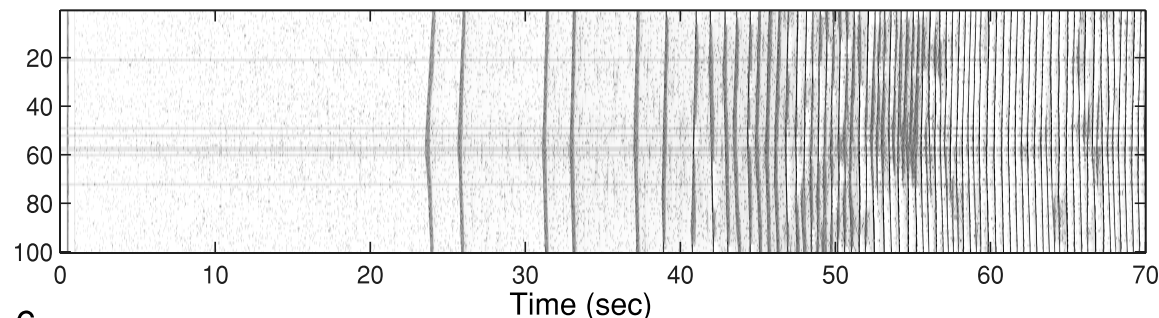

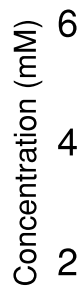
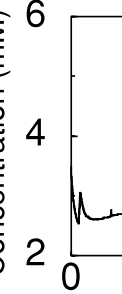

Time

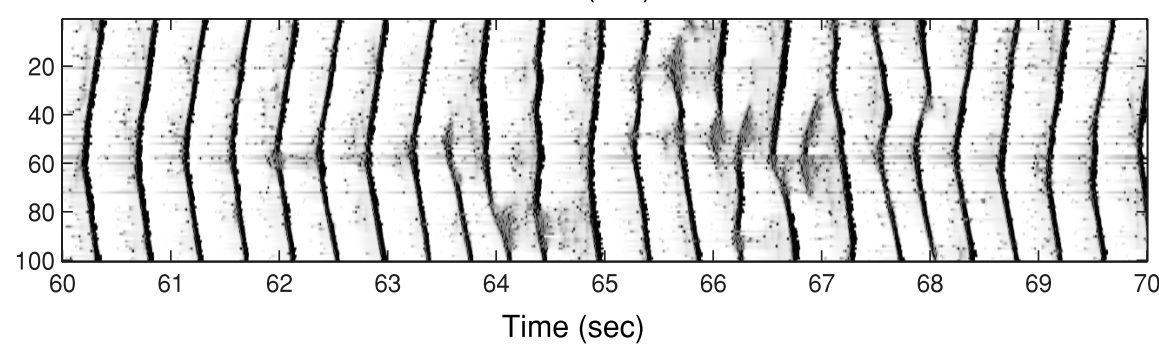

FIG. 9. Effect of IN-mediated inhibition. Random network activity was maintained by Poisson distributed inputs to PY cells and INs. $A$ : in control conditions, the network fired randomly with $\left[\mathrm{K}^{+}\right]_{\mathrm{o}}$ stabilized at relatively low level. $B$ : when $\mathrm{GABA}_{\mathrm{A}}$ conductance was blocked at $t=5 \mathrm{~s}$, increased firing led to the grow of $\left[\mathrm{K}^{+}\right]_{\mathrm{o}}$ and bursting. $\left[\mathrm{K}^{+}\right]_{\mathrm{o}}$ evolution for neuron 35 is shown. extracellular space; however, most of $\mathrm{K}^{+}$ions then diffused away so the total increase in $\left[\mathrm{K}^{+}\right]_{\mathrm{o}}$ was not sufficient to induce paroxysmal oscillations. This suggests that diffusion can control the "normal" level of network activity.

\section{Effect of $\mathrm{K}^{+}$pump on network oscillations}

$\mathrm{K}^{+}$pumps were blocked at $t=5 \mathrm{~s}$ in a group of cells (numbers $30-50$ ) in the network (Fig. 10). Initially random firing that was maintained by random excitatory input as described in the previous section. Elevation of $\left[\mathrm{K}^{+}\right]_{\mathrm{o}}$ after pump blocking progressively depolarized PY neurons thus increasing their frequency of firing, which led to the release of additional $\mathrm{K}^{+}$into the extracellular space. Starting at about $t=12 \mathrm{~s}$, many cells in the network showed bursting, which continued even after random external input was removed at $t=50 \mathrm{~s}$. Under these conditions, the neurons were locally synchronized similar to that observed after DC stimulation in the model with lateral diffusion (Fig. 8B).
During first 15-20 s after $\mathrm{K}^{+}$pumps were blocked in a group of cells, only neurons inside and near this group displayed oscillations. The size of bursting cluster of neurons increased progressively and a whole network started oscillating after $\sim 25 \mathrm{~s}$ after $\mathrm{K}^{+}$pumps blocking.

\section{Effect of glial buffering on network oscillations}

When glial buffering was blocked in a group of cells (numbers 30-50) from the same network as studies in the preceding text, slow $2-\mathrm{Hz}$ bursting with spike inactivation immediately started (Fig. 11A). Without lateral $\mathrm{K}^{+}$diffusion, this bursting in a group of cells did not have significant effect on the rest of the PY population (see Fig. $11 A$ ). As $\left[\mathrm{K}^{+}\right]_{\mathrm{o}}$ increased, the frequency of oscillations also increased, and $\sim 15$ s later the oscillations stopped with the PY cells' membrane potential permanently "locked" into the depolarized state. 

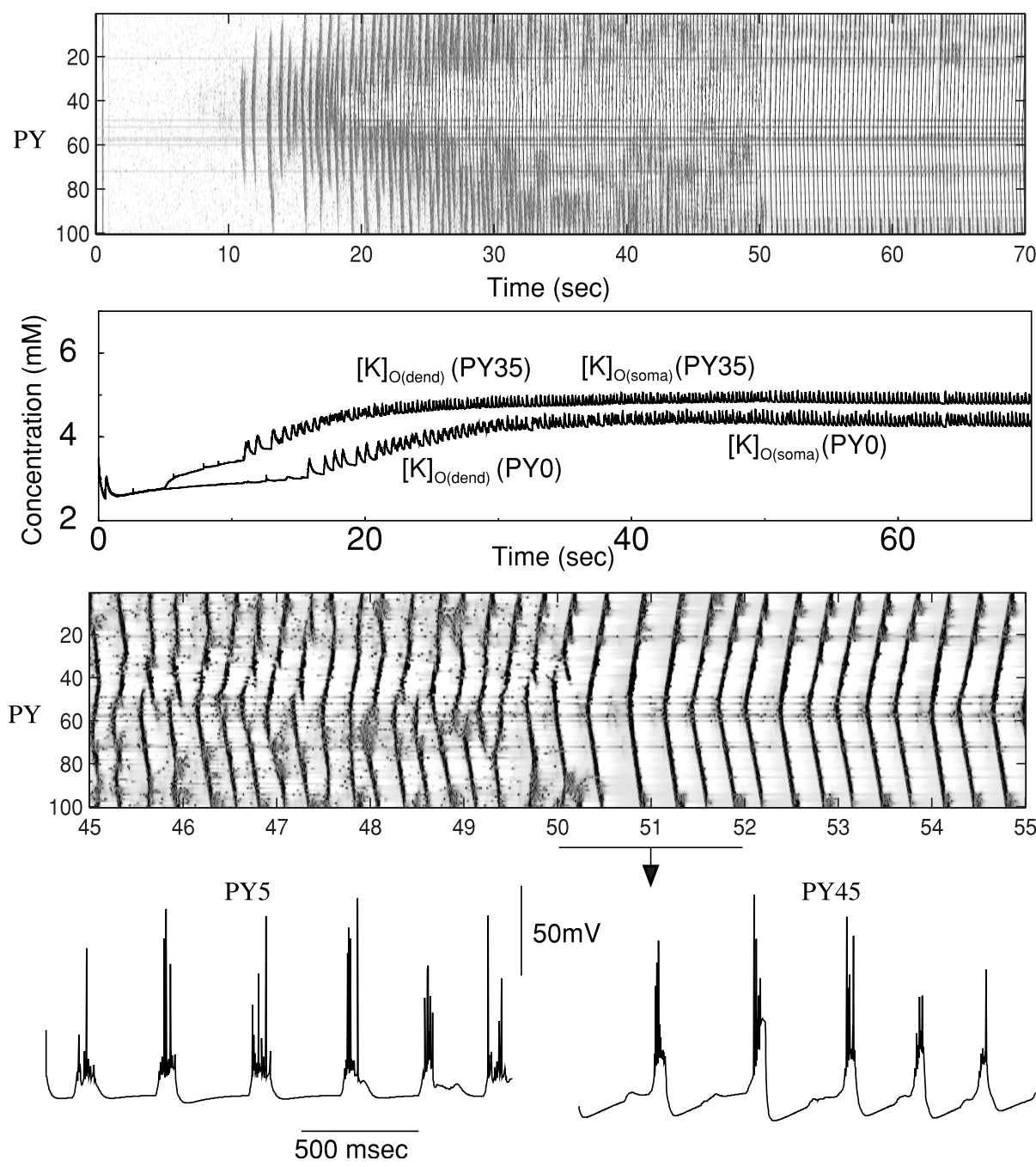

$\nabla$

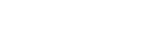

PY45

When random external stimulation was removed at $t=50 \mathrm{~s}$, all the cells became silent.

Including lateral PY-PY $\mathrm{K}^{+}$diffusion to the model dramatically changed the firing patterns of all neurons (Fig. 11B). The flow of $\mathrm{K}^{+}$out of the region where glial buffering was blocked prevented permanent depolarization, so the cells kept oscillating at $\sim 3 \mathrm{~Hz}$. It also increased $\left[\mathrm{K}^{+}\right]_{\mathrm{o}}$ in the surrounding region; the cells there fired at a higher frequency and eventually started to burst (see Fig. 11B). This bursting continued after removing external stimulation at $t=50 \mathrm{~s}$. Similar to the results discussed in the previous sections, the bursts started in the middle of the network in the region where a few closely located PY neurons with $I_{\mathrm{h}}$ were found. Figure 11 also illustrates the $\left[\mathrm{K}^{+}\right]_{\mathrm{o}}$ dynamics near two different PY cells, one belonging to the region where glial buffering was blocked (cell 35 ) and another outside this region (cell 0). In the first cell, $\left[\mathrm{K}^{+}\right]_{\mathrm{o}}$ increased immediately after removal of the glial buffering. In the remote neuron, $\left[\mathrm{K}^{+}\right]_{\mathrm{o}}$ increase was much more gradual and the $\mathrm{K}^{+}$concentration stabilized at lower level.

\section{I S C U S S I O N}

In vivo recordings from intact cat neocortex and cortical slab preparations suggest a cortical origin for SW and PSW electrographic seizures (Neckelmann et al. 1998; Steriade and
FIG. 10. Effect of $\mathrm{K}^{+}$pump on network activity. Blocking the $\mathrm{K}^{+}$pump at $t=5 \mathrm{~s}$ led to increase of $\left[\mathrm{K}^{+}\right]_{\mathrm{o}}$ and bursting. Oscillations continued after removing random external input at $t=50 \mathrm{~s}$. A group of cell with $I_{\mathrm{h}}$ led the network oscillations. 

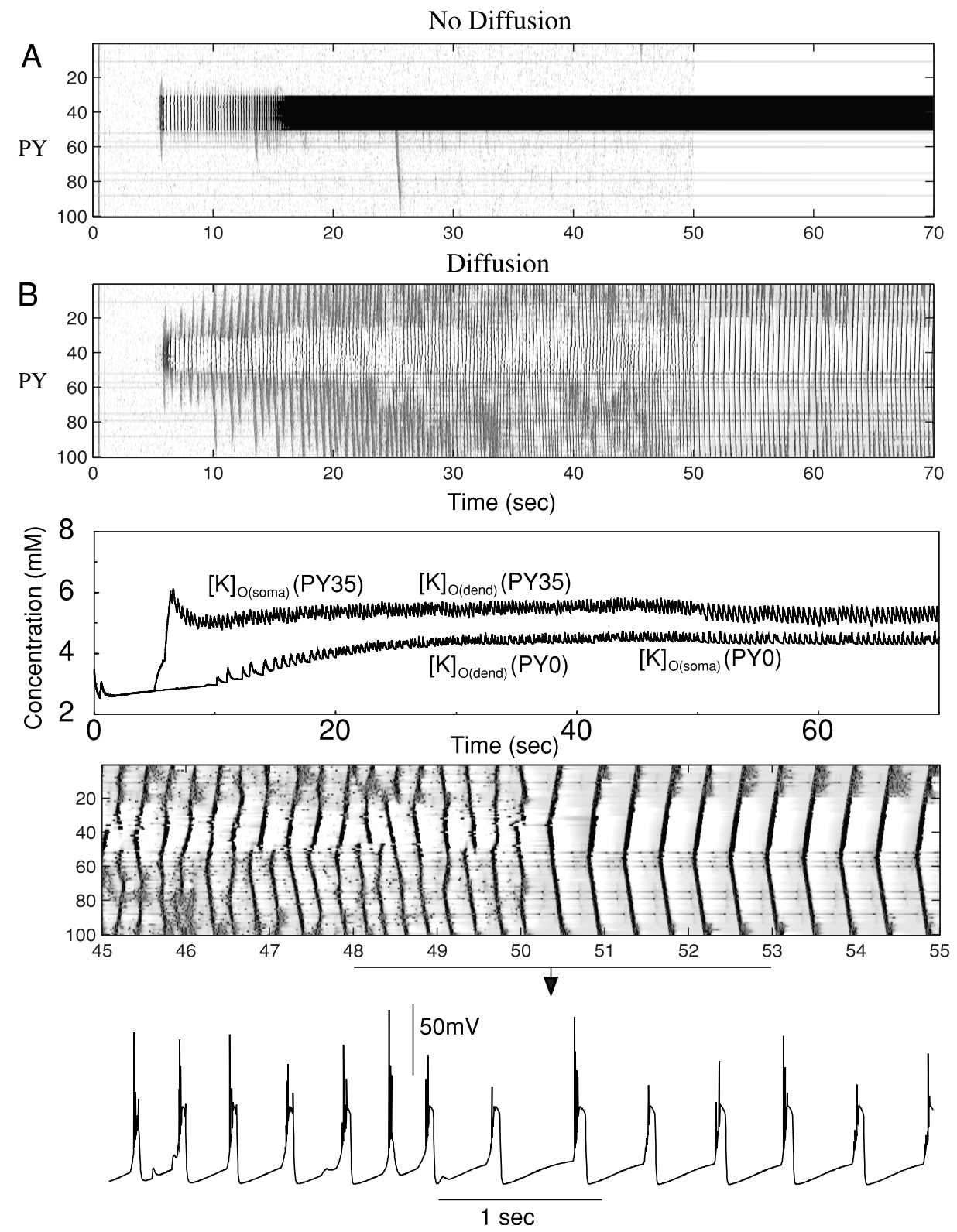

FIG. 11. Effect of glial buffering on network activity. Glial buffering system was blocked in a group of cells (numbers $30-50$ ) at $t=5 \mathrm{~s}$. $A$ : low-frequency bursting was found in this group and was followed by permanent spike inactivation at about $t=20 \mathrm{~s}$. $B$ : when lateral (between cell) diffusion of $\mathrm{K}^{+}$was introduced to the model, the cells outside the group also increased firing. After external random input to the network was removed at $t=50 \mathrm{~s}$, the network displayed periodic oscillations at $\sim 3 \mathrm{~Hz}$.
In this study, we tested the hypothesis that a combination of intrinsic conductances and elevated $\left[\mathrm{K}^{+}\right]_{\mathrm{o}}$ can be sufficient to initiate 2- to $3-\mathrm{Hz}$ SW/PSW oscillations. Increased $\left[\mathrm{K}^{+}\right]_{\mathrm{o}}$ may occur due to spontaneous increase in local neuronal firing (see Fig. 1). In the model, the extracellular $\mathrm{K}^{+}$concentration was continuously computed based on $\mathrm{K}^{+}$currents and $\mathrm{K}^{+}$pumps; extracellular $\mathrm{K}^{+}$also depended on glial buffering. Increase in $\left[\mathrm{K}^{+}\right]_{\mathrm{o}}$ affected the reversal potentials for $\mathrm{K}^{+}$-mediated currents, such as $I_{\mathrm{Km}}, I_{\mathrm{K}(\mathrm{Ca})}, I_{\mathrm{K}(\text { leak })}$, and $I_{\mathrm{h}}$. Previously we showed with a simplified model of the cortical network that $\mathrm{K}^{+}$dependent enhancement of $I_{\mathrm{h}}$, including $I_{\mathrm{h}}$ reversal potential depolarization and increase of the maximal conductance (Spain et al. 1987), is sufficient to produce $2-$ to $3-\mathrm{Hz}$ bursting (Timofeev et al. 2002a). Here the elevation of $\left[\mathrm{K}^{+}\right]_{\mathrm{o}}$ was modeled with different protocols, including intensive stimulation leading to high-frequency firing, direct $\mathrm{K}^{+}$injection to the extracellular space, blocking the $\mathrm{K}^{+}$pump, and blocking the glial buffering system. In a single PY neuron when $[\mathrm{K}]_{\mathrm{o}}$ increased sufficiently, slow 2- to $3-\mathrm{Hz}$ bursting was often accompanied by spike inactivation. Typically, after one to two spikes the cell membrane potential became "locked" into the depolarized state maintained by the effects of $I_{\mathrm{Na}}$ and $I_{\mathrm{K}}$. An increase of the intracellular $\mathrm{Ca}^{2+}$ mediated by a high-threshold $\mathrm{Ca}^{2+}$ current eventually increased $I_{\mathrm{K}(\mathrm{Ca})}$ to the level where the depolarized state became unstable and the membrane potential rapidly hyperpolarized. This hyperpolarization led to $I_{\mathrm{h}}$ activation and slow repolarization to the level where $I_{\mathrm{Na}(\mathrm{p})}$ became activated and initiated the next burst. The frequency of this bursting depended on many intrinsic conductances, especially $g_{\mathrm{K}(\mathrm{Ca})}$ and $g_{\mathrm{h}}$. We also tested the model where both $\mathrm{K}^{+}$and $\mathrm{Na}^{+}$ionic concentrations were updated based on the currents flow and $\mathrm{Na}^{+} / \mathrm{K}^{+}$pump and found that $\left[\mathrm{K}^{+}\right]_{\mathrm{o}}$ had a major effect on cell dynamics.

The role of elevated $\left[\mathrm{K}^{+}\right]_{\mathrm{o}}$ in producing synchronized neuronal bursts through the shift of the $\mathrm{K}^{+}$reversal potential was previously studied in hippocampal slice models (Traub and Dingledine 1990). In Kager et al. (2000), periodic bursting after $\left[\mathrm{K}^{+}\right]_{\mathrm{o}}$ increase was described in a single cell; however, in 
this model, bursts occurred at very low frequency (1 every $10-15 \mathrm{~s})$ that might be attributed to the lack of $I_{\mathrm{K}(\mathrm{Ca})}$. In recordings from granule cells of the dentate gyrus of the hippocampus at different levels of ionic concentrations in vitro, a simultaneous increase in $\left[\mathrm{K}^{+}\right]_{\mathrm{o}}$ and decrease in $\left[\mathrm{Ca}^{2+}\right]_{\mathrm{o}}$ caused cellular bursts to appear at $\mathrm{K}^{+} / \mathrm{Ca}^{2+}$ concentrations that were previously recorded in vivo before the onset of synchronized reverberatory seizure activity (Pan and Stringer 1997).

The firing patterns found in our model had close similarities with those observed in vivo. The progressive increase in the firing rate preceding periodic bursting in our model (see, e.g., Figs. 3 and $8-11$ ) was similar to the increase in frequency of spontaneous neuronal firing prior to the seizure found in vivo (see Fig. 1). High-frequency bursting with or without spike inactivation in the different model neurons (see, e.g., Figs. 3 and 8) was also observed in vivo (see e.g., Figs. 1 and 2 in Timofeev et al. 2004). The "lock" of the membrane potential in the depolarized state found in the model for very high levels of $\left[\mathrm{K}^{+}\right]_{\mathrm{o}}$ (Fig. $4 C$ ) has also been observed in vivo (see Fig. 2 in Timofeev et al. 2004). Fast 10- to $15-\mathrm{Hz}$ oscillations found in the model for particular region of $\left[\mathrm{K}^{+}\right]_{\mathrm{o}}$ values (see Figs. 3-5), were similar to fast runs in vivo (see e.g., Fig. 2, middle, in Timofeev et al. 2004).

In exploring the effects of different intrinsic currents, we found that a combination of a few conductances such as $g_{\mathrm{Ca}}$, $g_{\mathrm{Na}(\mathrm{p})}, g_{\mathrm{h}}$, and $g_{\mathrm{K}(\mathrm{Ca})}$ was sufficient to produce periodic bursting. When maximal conductances for $I_{\mathrm{Ca}}, I_{\mathrm{Na}(\mathrm{p})}$, or $I_{\mathrm{h}}$ were reduced below a certain level no bursting occurred after $\left[\mathrm{K}^{+}\right]_{\mathrm{o}}$ elevation. Eliminating $I_{\mathrm{K}(\mathrm{Ca})}$ could produce a permanent "lock" of the membrane potential in the depolarized state. The importance of cooperative effects of several conductances for generating spreading depression has been previously shown in a computational study (Kager et al. 2000). In our model, paroxysmal oscillations were obtained without including a lowthreshold $\mathrm{Ca}^{2+}$ (T-type) current, which was important in some other modeling studies (Destexhe et al. 2001). Synaptic conductances also were not required. These results are consistent with data from hippocampal slices where increasing neuronal excitability (by removing extracellular $\mathrm{Mg}^{2+}$ and increasing extracellular $\mathrm{K}^{+}$) in the presence of $\mathrm{Cd}^{2+}$, a nonselective $\mathrm{Ca}^{2+}$ channel antagonist, or veratridine, a persistent sodium conductance enhancer, induced spontaneous nonsynaptic epileptiform activity (Bikson et al. 2002). In recordings from rat hippocampal slices with high $\left[\mathrm{K}^{+}\right]_{\mathrm{o}}$, the local generation of population bursts in CA1 was caused by intrinsically bursting pyramidal cells, which recruit and synchronize other neurons (Jensen and Yaari 1997).

In the network model that included layers of PY cells, IN cells, and lateral $\mathrm{K}^{+}$diffusion between PY cells, an increase of $\left[\mathrm{K}^{+}\right]_{\mathrm{o}}$ in a small region was generally sufficient to maintain paroxysmal oscillations in the whole network. This local $\left[\mathrm{K}^{+}\right]_{\mathrm{o}}$ increase could be induced by intense stimulation or by disrupting homeostatic $\left[\mathrm{K}^{+}\right]_{\mathrm{o}}$ mechanisms; $\mathrm{K}^{+}$diffusion increased the excitability of the neighboring cells so the whole network became oscillatory. The cells inside the region of high $\left[\mathrm{K}^{+}\right]_{\mathrm{o}}$ usually oscillated with spike inactivation while remote cells displayed high-frequency bursts. Paroxysmal discharges propagated from the single most active network focus. This focus typically included cells with the highest $I_{\mathrm{h}}$. The threshold for initiating paroxysmal oscillations was lower in the network model compared with isolated PY cell. AMPA- and NMDA- mediated synaptic currents enhanced oscillations especially in the region surrounding paroxysmal foci where neurons fired high-frequency bursts without spike inactivation. However, NMDA currents were not necessary to maintain network bursting as long as $\left[\mathrm{K}^{+}\right]_{\mathrm{o}}$ was sufficiently elevated. This result is an agreement with data obtained in a companion paper where paroxysmal oscillations were found under ketamine anesthesia that blocks NMDA synaptic transmission (Timofeev et al. 2004). The role of long-range spatial buffering of $\mathrm{K}^{+}$operated by glia in synchronizing and/or spreading of paroxysmal oscillations has been recently studied in vivo (Amzica et al. 2002).

The level of $\left[\mathrm{K}^{+}\right]_{\mathrm{o}}$ in the model was determined by $\mathrm{K}^{+}$mediated currents, the $\mathrm{K}^{+}$pump, and glial buffering. When either the $\mathrm{K}^{+}$pump or glial buffering failed to perform normally, the $\left[\mathrm{K}^{+}\right]_{\mathrm{o}}$ increase led to paroxysmal bursting. Recent studies of physiological properties of glial cells from acute slices of biopsies from patients operated for intractable mesiotemporal lobe epilepsy indicate that glial $\mathrm{K}^{+}$buffering could be impaired at the seizure focus, thus contributing to the pathophysiology of seizures (Bordey and Sontheimer 1998). In the model, excessive firing induced by external stimulation could produce $\mathrm{K}^{+}$outward flow exceeding the capacity of the $\mathrm{K}^{+}$pump and glial buffering system and could result in periodic bursting. Cell swelling during seizures (Jing et al. 1994; Perez-Pinzon et al. 1995) would restrict interstitial space and further amplify increase of $\left[\mathrm{K}^{+}\right]_{0}$. If all the cells in the model displayed bursts with spike inactivation, the lack of spiking reduced the outward flow of $\mathrm{K}^{+}$and normal level of $\left[\mathrm{K}^{+}\right]_{\mathrm{o}}$ could be restored after a certain period of time, which eventually terminated the oscillations. The oscillations could last longer in a heterogeneous network when bursting with spike inactivation in a small group of cells maintained firing in the neighbor cortical population through synaptic coupling. In return, high-frequency bursts in this surrounding region helped to maintain a high level of $\left[\mathrm{K}^{+}\right]_{\mathrm{o}}$ inside the central focus.

Changes in $\left[\mathrm{K}^{+}\right]_{\mathrm{o}}$ could explain transitions between slow 2to $3-\mathrm{Hz}$ bursting and fast runs as observed in vivo (Timofeev et al. 1998). In the model, the oscillatory pattern (slow bursting or fast run) depended on the absolute level of $\left[\mathrm{K}^{+}\right]_{\mathrm{o}}$ and also on the relative levels of $\left[\mathrm{K}^{+}\right]_{\mathrm{o}}$ around soma and dendrites (Fig. 5). In particular, slow bursting could be replaced by fast $\sim 10-\mathrm{Hz}$ oscillations when the level of $\left[\mathrm{K}^{+}\right]_{\mathrm{o}}$ was reduced because of spike inactivation (see e.g., Fig. 3).

Our model suggests that increase of $\left[\mathrm{K}^{+}\right]_{\mathrm{o}}$ can transform random awake-like activity into paroxysmal oscillations reminiscent of electrographic SW/PSW seizures. This model predicts that paroxysmal bursting after $\left[\mathrm{K}^{+}\right]_{\mathrm{o}}$ increase depends on the balance of a few intrinsic conductances, can be generated in the isolated cortical network, and does not rely exclusively on any synaptic conductances. In acute conditions, brain lesions produce an immediate increase in $\left[\mathrm{K}^{+}\right]_{\mathrm{o}}$ from intracellular pools that may trigger paroxysmal activity (Topolnik et al. 2003). Data from patients with severe brain injury indicate that posttraumatic neuronal excitation by excitatory amino acids leads to an increase in $\left[\mathrm{K}^{+}\right]_{\mathrm{o}}$, probably due to ion channel activation (Reinert et al. 2000). Thus increased risk for early epileptogenesis after brain trauma may be attributed to the increase of $\left[\mathrm{K}^{+}\right]_{0}$. 


\section{G R A N T S}

This research was supported by National Institutes of Neurological Disorders and Stroke Grant NS-40522, Human Frontier Science Program and the Canadian Institutes of Health Research (grants MT-3689 and MOP-37862). I. Timofeev is scholar of Fonds de la Recherch en Santé du Québec.

\section{REFERENCES}

Abbott LF, Varela JA, Sen K, and Nelson SB. Synaptic depression and cortical gain control. Science 275: 220-224, 1997.

Alzheimer C, Schwindt PC, and Crill WE. Modal gating of $\mathrm{Na}^{+}$channels as a mechanism of persistent $\mathrm{Na}^{+}$current in pyramidal neurons from rat and cat sensorimotor cortex. J Neurosci 13: 660-673, 1993.

Amzica F, Massimini M, and Manfridi A. Spatial buffering during slow and paroxysmal sleep oscillations in cortical networks of glial cells in vivo. J Neurosci 22: 1042-1053, 2002.

Bazhenov M, Timofeev I, Steriade M, and Sejnowski TJ. Cellular and network models for intrathalamic augmenting responses during $10-\mathrm{Hz}$ stimulation. J Neurophysiol 79: 2730-2748, 1998.

Bazhenov M, Timofeev I, Steriade M, and Sejnowski TJ. Model of thalamocortical slow-wave sleep oscillations and transitions to activated states. J Neurosci 22: 8691-8704, 2002.

Bikson M, Baraban SC, and Durand DM. Conditions sufficient for nonsynaptic epileptogenesis in the CA1 region of hippocampal slices. $J$ Neurophysiol 87: 62-71, 2002.

Bordey A and Sontheimer H. Properties of human glial cells associated with epileptic seizure foci. Epilepsy Res 32: 286-303, 1998.

Compte A, Sanchez-Vives MV, McCormick DA, and Wang XJ. Cellular and network mechanisms of slow oscillatory activity $(<1 \mathrm{~Hz})$ and wave propagations in a cortical network model. J Neurophysiol 89: 2707-2725, 2003.

D'Ambrosio R, Maris DO, Grady MS, Winn HR, and Janigro D. Impaired $\mathrm{K}(+)$ homeostasis and altered electrophysiological properties of post-traumatic hippocampal glia. J Neurosci 19: 8152-8162, 1999.

Destexhe A, Contreras D, and Steriade M. LTS cells in cerebral cortex and their role in generating spike-and-wave oscillations. Neurocomputing 38-40: 555-563, 2001.

Destexhe A, Mainen ZF, and Sejnowski TJ. Synthesis of models for excitable membranes, synaptic transmission and neuromodulation using a common kinetic formalism. J Comput Neurosci 1: 195-230, 1994.

Echlin FA and Battista A. Epileptiform seizures from chronic isolated cortex. Arch Neurol 9: 154-170, 1963.

Fisher RS, Pedley TA, and Prince DA. Kinetics of potassium movement in norman cortex. Brain Res 101: 223-237, 1976.

Galarreta $\mathbf{M}$ and Hestrin S. Frequency-dependent synaptic depression and the balance of excitation and inhibition in the neocortex. Nat Neurosci 1: 587-594, 1998.

Golomb D and Amitai Y. Propagating neuronal discharges in neocortical slices: computational and experimental study. J Neurophysiol 78: 11991211, 1997.

Golomb D and Ermentrout GB. Bistability in pulse propagation in networks of excitatory and inhibitory populations. Phys Rev Lett 86: 4179-4182, 2001.

Grafstein B. Mechanism of spreading cortical depression. J Neurophysiol 19: 154-171, 1957.

Grafstein B and Sastry PB. Some preliminary electrophysiological studies on chronic neuronally isolated cerebral cortex. Electroencephalogr Clin Neurophysiol 9: 723-725, 1957.

Gutfreund Y, Yarom Y, and Segev I. Subthreshold oscillations and resonant frequency in guinea-pig cortical neurons: physiology and modelling. J Physiol 483: 621-640, 1995.

Gutnick MJ, Connors BW, and Prince DA. Mechanisms of neocortical epileptogenesis in vitro. J Neurophysiol 48: 1321-1335, 1982.

Herreras $\mathbf{O}$ and Somjen GG. Analysis of potential shifts associated with recurrent spreading depression and prolonged unstable spreading depression induced by microdialysis of elevated $\mathrm{K}^{+}$in hippocampus of anesthetized rats. Brain Res 610: 283-294, 1993.

Jensen MS and Yaari Y. Role of intrinsic burst firing, potassium accumulation, and electrical coupling in the elevated potassium model of hippocampal epilepsy. J Neurophysiol 77: 1224-1233, 1997.

Jing J, Aitken PG, and Somjen GG. Interstitial volume changes during spreading depression (SD) and SD-like hypoxic depolarization in hippocampal tissue slices. J Neurophysiol 71: 2548-2551, 1994.
Kager H, Wadman WJ, and Somjen GG. Simulated seizures and spreading depression in a neuron model incorporating interstitial space and ion concentrations. J Neurophysiol 84: 495-512, 2000.

Kay AR, Sugimori M, and Llinas R. Kinetic and stochastic properties of a persistent sodium current in mature guinea pig cerebellar Purkinje cells. J Neurophysiol 80: 1167-1179, 1998.

Leschinger A, Stabel J, Igelmund P, and Heinemann U. Pharmacological and electrographic properties of epileptiform activity induced by elevated $\mathrm{K}^{+}$and lowered $\mathrm{Ca}^{2+}$ and $\mathrm{Mg} 2+$ concentration in rat hippocampal slices. Exp Brain Res 96: 230-240, 1993.

Mainen ZF and Sejnowski TJ. Influence of dendritic structure on firing pattern in model neocortical neurons. Nature 382: 363-366, 1996.

Moody WJ, Futamachi KJ, and Prince DA. Extracellular potassium activity during epileptogenesis. Exp Neurol 42: 248-263, 1974.

Neckelmann D, Amzica F, and Steriade M. Spike-wave complexes and fast components of cortically generated seizures. III. Synchronizing mechanisms. J Neurophysiol 80: 1480-1494, 1998.

Niedermeyer E. Lennox-Gastaut syndrome. Clinical description and diagnosis. Adv Exp Med Biol 497: 61-75, 2002.

Pan E and Stringer JL. Role of potassium and calcium in the generation of cellular bursts in the dentate gyrus. J Neurophysiol 77: 2293-2299, 1997.

Perez-Pinzon MA, Tao L, and Nicholson C. Extracellular potassium, volume fraction, and tortuosity in rat hippocampal CA1, CA3, and cortical slices during ischemia. $J$ Neurophysiol 74: 565-573, 1995.

Pinault D, Leresche N, Charpier S, Deniau JM, Marescaux C, Vergnes M, and Crunelli V. Intracellular recordings in thalamic neurones during spontaneous spike and wave discharges in rats with absence epilepsy. J Physiol 509: 449-456, 1998.

Reinert M, Khaldi A, Zauner A, Doppenberg E, Choi S, and Bullock R. High level of extracellular potassium and its correlates after severe head injury: relationship to high intracranial pressure. J Neurosurg 93: 800-807, 2000.

Reuveni I, Friedman A, Amitai Y, and Gutnick MJ. Stepwise repolarization from $\mathrm{Ca}^{2+}$ plateaus in neocortical pyramidal cells: evidence for nonhomogeneous distribution of HVA Ca ${ }^{2+}$ channels in dendrites. J Neurosci 13: 4609-4621, 1993.

Schwartzkroin PA and Prince DA. Cellular and field potential properties of epileptogenic hippocampal slices. Brain Res 147: 117-130, 1978.

Sharpless SK and Halpern LM. The electrical excitability of chronically isolated cortex studied by means of permanently implanted electrodes. Electroencephalogr Clin Neurophysiol 14: 244-255, 1962.

Somjen GG and Muller M. Potassium-induced enhancement of persistent inward current in hippocampal neurons in isolation and in tissue slices. Brain Res 885: 102-110, 2000.

Spain WJ, Schwindt PC, and Crill WE. Anomalous rectification in neurons from cat sensorimotor cortex. J Neurophysiol 57: 1555-1576, 1987.

Steriade M. Interneuronal epileptic discharges related to spike-and-wave cortical seizures in behaving monkeys. Electroencephalogr Clin Neurophysiol 37: 247-263, 1974.

Steriade M, Amzica F, Neckelmann D, and Timofeev I. Spike-wave complexes and fast components of cortically generated seizures. II. Extra- and intracellular patterns. J Neurophysiol 80: 1456-1479, 1998a.

Steriade $\mathbf{M}$ and Contreras D. Relations between cortical and thalamic cellular events during transition from sleep patterns to paroxysmal activity. J Neurosci 15: 623-642, 1995.

Steriade $\mathbf{M}$ and Contreras D. Spike-wave complexes and fast components of cortically generated seizures. I. Role of neocortex and thalamus. J Neurophysiol 80: 1439-1455, 1998.

Steriade M, Timofeev I, Grenier F, and Durmuller N. Role of thalamic and cortical neurons in augmenting responses and self- sustained activity: dual intracellular recordings in vivo. J Neurosci 18: 6425-6443, 1998b.

Timofeev I, Bazhenov M, Sejnowski T, and Steriade M. Cortical hyperpolarization-activated depolarizing current takes part in the generation of focal paroxysmal activities. Proc Natl Acad Sci USA 99: 9533-9537, 2002a.

Timofeev I, Grenier F, Bazhenov M, Sejnowski TJ, and Steriade M. Origin of slow cortical oscillations in deafferented cortical slabs. Cereb Cortex 10: 1185-1199, 2000.

Timofeev I, Grenier F, and Steriade M. Contribution of intrinsic cellular factors in the generation of cortically generated electrographic seizures. J Neurophysiol 92: 1133-1143, 2004.

Timofeev I, Grenier F, and Steriade M. The role of chloride-dependent inhibition and the activity of fast-spiking neurons during cortical spike-wave electrographic seizures. Neuroscience 114: 1115-1132, 2002b. 
Timofeev I, Grenier F, and Steriade M. Spike-wave complexes and fast components of cortically generated seizures. IV. Paroxysmal fast runs in cortical and thalamic neurons. J Neurophysiol 80: 1495-1513, 1998.

Topolnik L, Steriade M, and Timofeev I. Partial cortical deafferentation promotes development of paroxysmal activity. Cereb Cortex 13: 883-893, 2003.

Traub RD and Dingledine R. Model of synchronized epileptiform bursts induced by high potassium in CA3 region of rat hippocampal slice. Role of spontaneous EPSPs in initiation. J Neurophysiol 64: 1009-1018, 1990.
Traub RD, Wong RK, Miles R, and Michelson H. A model of a CA3 hippocampal pyramidal neuron incorporating voltage-clamp data on intrinsic conductances. J Neurophysiol 66: 635-650, 1991.

Tsodyks MV and Markram $\mathbf{H}$. The neural code between neocortical pyramidal neurons depends on neurotransmitter release probability. Proc Natl Acad Sci USA 94: 719-723, 1997.

Turrigiano GG. Homeostatic plasticity in neuronal networks: the more things change, the more they stay the same. Trends Neurosci 22: 221-227, 1999. 